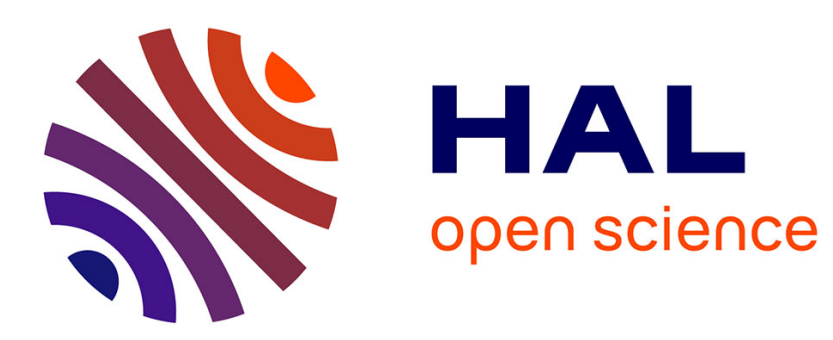

\title{
The semantic roots of positive polarity: epistemic modal verbs and adverbs in English, Greek and Italian
}

\author{
Anastasia Giannakidou, Alda Mari
}

\section{To cite this version:}

Anastasia Giannakidou, Alda Mari. The semantic roots of positive polarity: epistemic modal verbs and adverbs in English, Greek and Italian. Linguistics and Philosophy, 2018, 41 (6), pp.623-664. 10.1007/s10988-018-9235-1 . ijn_02194773

\section{HAL Id: ijn_02194773 \\ https://hal.science/ijn_02194773}

Submitted on 26 Jul 2019

HAL is a multi-disciplinary open access archive for the deposit and dissemination of scientific research documents, whether they are published or not. The documents may come from teaching and research institutions in France or abroad, or from public or private research centers.
L'archive ouverte pluridisciplinaire HAL, est destinée au dépôt et à la diffusion de documents scientifiques de niveau recherche, publiés ou non, émanant des établissements d'enseignement et de recherche français ou étrangers, des laboratoires publics ou privés. 


\title{
The semantic roots of positive polarity: epistemic modal verbs and adverbs in English, Greek and Italian
}

\author{
Anastasia Giannakidou and Alda Mari \\ University of Chicago and Institut Jean Nicod \\ 2018 \\ Linguistics and Philosophy
}

Final version at: https://link.springer.com/article/10.1007/s10988-018-9235-1

\begin{abstract}
Epistemic modal verbs and adverbs of necessity are claimed to be positive polarity items. We study their behavior by examining modal spread, a phenomenon that appears redundant or even anomalous, since it involves two apparent modal operators being interpreted as a single modality. We propose an analysis in which the modal adverb is an argument of the MUST modal, providing a meta-evaluation $\mathcal{O}$ which ranks the Ideal, stereotypical worlds in the modal base as better possibilities than the Non-Ideal worlds in it. MUST and possibility modals differ in that the latter have an empty $\mathcal{O}$, a default that can be negotiated. Languages vary in the malleability of this parameter. Positive polarity is derived as a conflict between the ranking imposed by $\mathcal{O}$ - which requires that the Ideal worlds be better possibilities than Non-Ideal worlds - and the effect of higher negation which renders the Ideal set non-homogenous. Applying the ordering over such a non-homogeneous set would express preference towards both $p$ and $\neg p$ worlds thus rendering the sentence uninformative. Negative polarity MUST and possibility modals, on the other hand, contain an empty $\mathcal{O}$, application of higher negation therefore poses no problem. This account is the first to connect modal spread to positive polarity of necessity modals, and captures the properties of both in a unified analysis.
\end{abstract}

\section{Modal verbs and adverbs: negation, modal spread}

In recent studies, interest in the interaction of modal verbs with negation has been rekindled (e.g., Iatridou and Zeijlstra 2013, Rubinstein, 2014, Homer 2015, Zeijlstra to appear). A core observation is that necessity modals such as must scope above negation, but possibility modals scope below:

(1) Ariadne must not be a doctor. (= It must be the case that Ariadne is not a doctor).

(2) Ariadne must not eat meat. (Ariadne is a vegetarian).

(3) a. Ariadne cannot be a doctor.

b. Ariadne cannot talk to Dean.

(4) a. Ariadne doesn't have to be a doctor (to apply for this job).

b. Ariadne doesn't need to spend a lot of money (for Jason't birthday gift). 
The English modal must, in both epistemic and deontic use, is interpreted with scope above negation. Can, on the other hand, takes scope inside negation, on a par with modals such as have to, need in (4). These scope constraints are reminiscent of polarity, and van der Wouden (1994) proposed indeed that need is a negative polarity item (NPI), identifying similar NPI modals in Dutch (hoeven) and German (brauchen). If the necessity need is an NPI, then its counterpart must must be a positive polarity item (PPI), since it escapes the scope of negation.

This basic polarity contrast of English has been reproduced in a number of languages, and though the data are not always exactly parallel (in part depending on what the actual modal verb system is in each language), the general tendency is that a necessity modal which is not an NPI will tend to scope above negation. In this paper, we will focus on the epistemic variants which have generally received less attention than the deontic ones.

Our main focus will be the realization of epistemic necessity in Greek and Italian. We show below that Italian and Greek equivalents of must are also PPIs:
a. Gianni deve
essere malato.
John must.PRES.3SG be ill.
'John must be ill.'

b. Gianni non deve essere malato. MUST $>$ NEG

John not must.PRES.3SG be ill.

'John must not be ill.'
a. I Ariadne dhen prepi
na einai eggyos. MUST $>$ NEG
the Ariadne not must.PRES.3SG subj be pregnant
'Ariadne must not be pregnant (based on what I know).'
b. I Ariadne dhen xreiazete na ine eggyos. NEG > MUST
the Ariadne not need.3sg subj. be ill.
'Ariadne need not be pregnant (to be eligible for this leave).'

Giannakidou 1997 characterizes xreiazete 'need' in (6b) an NPI; like need, xreiazete tends to have deontic reading (see Iatridou and Zeijlstra 2013 for more discussion). Notice that in Greek and Italian, unlike English (must not), negation actually appears to the left of the modalthe logical scoping, however, is identical to English. (We discuss the syntax in more detail in Section 4). Italian and Greek employ the modal verbs dovere, prepi as equivalents to must, and lack single word equivalents of the English words should, ought, have to and the like. (Italian uses the modal dovere in the conditional for should, or uses essere tenuto for have to.). Such lexicalizations tend to be employed for priority modality (Portner 2009, Rubinstein 2014, Portner and Rubinstein 2016), i.e. a wide range type of modality that is not epistemic, but sets up a contrast of priority between options or goals. Deontic modality can be understood as a kind of priority modality (Portner 2009). For now, simply note that Greek and Italian align with many of the world's languages that lexicalize in the modal verb system only the basic distinction between a universal modal (prepi, dovere), and an existential (bori, potere) (see further Staraki 2013 for more discussion on Greek modals; Narogg 2012 for cross linguistic discussion.)

Given the data above, we can generalize that the universal epistemic modals must, dovere, prepi - which can jointly be referred to as MUST ${ }^{1}$ - are indeed PPIs, and we will ask the question: what makes MUST modals PPIs? The literature thus far emphasizes the syntactic aspects of the phenomenon, and a popular approach appeals to feature checking (Iatridou and Zeijlstra 2013, Zeijlstra to appear; and, partly Huitink 2012). We find the feature checking approach unsatisfactory for reasons to be made clear soon, and pursue a semantic explanation

\footnotetext{
${ }^{1}$ We use upper case as a cover term for related words in multiple languages; italics designate the linguistic expressions in specific languages.
} 
(see also e.g. Rubinstein 2014, Homer 2015). Our analysis crucially and newly rests on the behavior of MUST verbs and their co-occurrence with modal adverbs, which have also been characterized as PPIs (Nilsen 2004, Ernst 2009, Liu 2009, 2012).

Modal adverbs co-exist, crucially, with modal verbs in what we call modal spread. Modal spread is not typically discussed in the context of positive polarity, but we will argue that it is, in fact, instrumental in revealing additional structure in the modality that plays a key role in producing the polarity effect. As an illustration of modal spread, consider the examples below:

a. John must probably/certainly be sleeping.

b. John may possibly be a doctor.

Here we see must and may co-occurring with probably/certainly and possibly, respectively. Nilsen 2004 and Ernst 2009 observed the PPI behavior of modal adverbs in their discussion of speaker oriented adverbs. Focussing on modal spread, Lyons 1977 talks about 'harmony' in (7), (8) - the idea being that there is a concord running through the clause which results in the double realization of a single modality (Lyons 1977: 808; see also Willer 2013), on a par with other cases of concord such as negative concord, person or gender agreement. This observation, namely that there is one modality in these cases, is stable in most of the analyses of the phenomenon (Geurts and Huitink 2006, Huitink 2012,2014, Grosz 2010, a contrario Anand and Brasoveanu 2010). Syntactically, if we admit one modality in these cases, we are saying that there is no embedding of one modal operator to the other, and the two work together to produce a single modal structure. This situation is distinct from true embeddings:

It may turn out that Ariadne must give her speech this afternoon.

This is a genuine case of must embedded under may; notice also the clause boundary (that). (Embedding can also happen within one clause, of course, as in Ariadne may have to give her speech this afternoon).

If the modal verb is the modal operator, what is the semantic contribution of the adverb in modal spread? In more philosophical works it has been claimed that "iterating epistemic possibility operators adds no value in the semantics" (Yalcin 2007: 994), or "embedding an epistemic modal under another epistemic modal does not in general have any interesting semantic effects" (Willer 2013: 12). Though these statements were mostly made for embeddings, they reveal a concord perspective where some of multiple exponents of modality are semantically vacuous (just like, e.g., multiple exponents of negation in negative concord). Huitink 2012 and Moss 2015 , on the other hand, argue that the multiple exponents of modality have a semantic roleand Huitink in particular argues that the adverb presents the ordering source of the modal. This can be thought of as a 'contentful' perspective to modal spread, and our own account and the novel data to be presented in this paper agree with this perspective.

In understanding modal spread, we must also acknowledge that we are not always dealing with concord, and this fact by itself serves as an argument that the use of the adverb is contentful. Modal verbs and adverbs with apparently opposing forces can co-occur with a single modality reading, as (9) shows for Italian dovere co-occurring with forse 'maybe'.

(9) Le luci sono accese. Gianni deve forse essere a casa. (non-harmonic use)

The lights are switch-on. Gianni must maybe be at home.

'The lights are on. John must (\#maybe) be at home.'

Below is an attested example (see also Cui 2015 for a corpus study of modal concord). The discussion is about an archeological reconstruction of the town Castel Nuovo, near Naples. 
(10) Il vaso, che costituisce uno dei premi guadagnati dagli atleti negli agoni panatenaici di Atene, deve forse fare parte del corredo di una sepoltura ubicata non lontano dall'area di Castel Nuovo.

'The jar, which constitutes one of the prizes earned by the athletes in the pan-athenians olympics of Athens, must maybe belong to the kid of a burial located not far from the area of Castel Nuovo. ${ }^{2}$,

The same verb-adverb combination with opposing forces can be found in English, (11). Greek forbids it (12).

(11) So there must maybe be some glitch somewhere along the line or something that makes this happen. I am sure is a cache or technical glitchup. ${ }^{3}$

(12) \#Prepi isos na ine giatros.

must maybe subj be.3SG doctor

'He must probably/definitely be a doctor.'

Sentences like (10) and (11) have, to our knowledge, rarely been discussed in the literature (see Moss 2015), and every current theory of modal concord would claim that they lack a single modality reading. We will argue here, however, that they do have it, and it is for this reason that we use the neutral term 'modal spread' instead of 'concord' (or 'harmony'). Huitink 2012 states that conditions on the adverbs "really can only be decided on a case to case basis" (Huitink 2012:30), but we aspire to show that there are some general principles that delimit the set of possible interactions.

Apparent harmonic uses seem to be pervasive in Greek and Italian, just as in English:
a. Prepi malon/oposdhipote na ine giatros. must probably/definitely subj be.3sG doctor 'He must probably/definitely be a doctor.'
b. Deve probabilmente/sicuramente essere un dottore. must.3SG.PRES probably/certainly be a doctor. 'He must probably/definitely be a doctor.'

a. Prepi malon/oposhipote na efije noris. must probably/definitely subj left.3sG early.

b. Deve probabilmente/sicuramente essere partito presto. must.3SG.PRES probably/certainly be left early. 'He must have probably/definitely left early.'

To these causes conjointly, therefore, must probably be ascribed the very delicate light ring not having been noticed by the observers of the late transit of Venus. ${ }^{4}$

We see here the modal adverbs malon/probabilmente (probably), oposdhopote/certamente (definitely), etc. co-occur with prepi/dovere/must. In Greek and Italian, modal spread is very common and unmarked. We offered combinations with present and past tenses, to illustrate that the phenomenon is tense independent. We find the co-occurrence also with the future, see (16) (Bertinetto 1979, Mari 2009b, Giannakidou 2012, Giannakidou and Mari 2012a,2013):

\footnotetext{
${ }^{2}$ Source: http://www.comune.napoli.it/flex/cm/pages/ServeBLOB.php/L/IT/ IDPagina/1425/UT/systemPrint

${ }^{3}$ Source: https://www.blackhatworld. com/seo/ogads-com-mobile-cpa-cpi-incent-network-mobi $704909 /$ page-26. We thank Paul Portner for pointing this to us.

${ }^{4}$ Source: adsabs . harvard. edu/full/
} 
a. Arriverà certamente/probabilmente alle 4.

arrive.3SG.FUT certainly/probably at 4 .

'John will definitely/probably arrive at 4.'

b. O Janis tha erthi sigoura/malon stis 4 .

the John FUT come.3SG certainly/probably at $4 \mathrm{pm}$.

'John will definitely/probably arrive at 4.'

In Greek strong adverbs cannot co-occur with possibility bori/may/might (17-a)-(18-a).

a. \#Bori malon/oposdhipote na efije noris. may probably/definitely subj left.3sG early.

b. Può probabilmente essere partito presto.

Can.3SG.PRES probably/certainly be left early.

'He may have probably/definitely left early.'

a. \#Bori malon na ine giatros. may probably subj be.3sG doctor.

b. Può probabilmente essere un dottore. may.3SG.PRES probably/certainly be a doctor.

'He may probably be a doctor.'

In Italian and English, on the other hand, weak modals can co-occur with strong adverbs (19)-(20), just as strong modals can co-occur with weak adverbs. ${ }^{5}$ In (20), we can be certain that the existential modal is epistemic insofar as it embeds a stative, and cannot be coerced into an eventive reading with the abilitative (or circumstantial) interpretation of potere (might). We also see in the second sentence ("no matter how the facts were settled') that the truth is not established and that the first sentence is described as expressing a conjecture. In this attested example, potere combines with probabilmente (probably). Notice a similar combination in English (20):

... e a questa circostanza può probabilmente essere dovuto il fatto che egli fosse arrivato al nono compleanno. Comunque stessero le cose, in ogni modo, era il suo nono compleanno.

'and the fact that he reached his ninth birthday might probably be due to these circumstances. No matter how the facts where settled, in any case, it was his ninth birthday. ${ }^{6}$

In some cases, however, the psychosis might definitely be due to anxieties and conflicts associated with the pregnancy. ${ }^{7}$

On the other hand, the possibility adverb is always grammatical with possibility modals in Greek, Italian and English:

\footnotetext{
${ }^{5} \mathrm{An}$ anonymous reviewer suggests that probably is an existential adverb. We disagree, and here is why. First, the data here indicate that probably combines with universal modals. Secondly, consider that the adverb necessarily, which would be the uncontested universal, tends to not be used epistemically in languages. Its closest equivalent, obligatorily, has deontic flavor. This leaves probably in the context of epistemic MUST and should as the universal adverb, and we are not aware of any analysis that argues otherwise.

${ }^{6}$ Source: https://books.google.fr/books?isbn=8804536829

${ }^{7}$ Source: https: / / books. google. com/books? id=c6JPyfOBZYIC\&pg=PA $74 \& l$ pg $=P A 74 \& d q=$ $\backslash \div 22 \mathrm{might}+$ definitely $\div 22 \&$ source=bl\&ots=LXLgsQVXT j\&sig=S5u 9MC jN4HwRHnfYTs_ yQOSbL9Y\&hl=fr\&sa=X\&ved=0 ahUKEw jp-4Xm36XVAhUJh1QKHWPFCVA 4 ChDoAQg 5MAQ\#v=

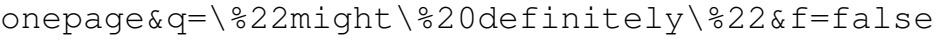


a. Bori isos na efije noris. may maybe subj left.3sG early

b. Può forse essere partito presto.

Can.3sg.pres maybe be left early.

'He may have possibly left early.'

(22) a. Bori isos na ine giatros.

may maybe subj be.3SG doctor

b. Può forse essere un dottore.

can.3SG.PRES maybe be a doctor.

'He may possibly be a doctor.'

(23) The homework might maybe not expressly state that you want a thesis declaration since your teacher might suppose you may comprise one. ${ }^{8}$

We can summarize the facts above in the following three generalizations:

1. Modal matching appears to be the general case, attested in all three languages (Greek, Italian, English), as well as Dutch (Geurts and Huitink 2006, Huitink 2012,2014), and German (Grosz 2012).

2. Modal spread also allows non-matching. It appears to be a more restricted option, a fact that needs to be explained.

3. Languages are subject to variation with respect to whether they allow non-matching (Italian and English do, but Greek doesn't).

Importantly, the modal adverbs that participate in modal spread tend to be positive: probably, definitely, maybe. Negative incarnations of necessity(like) epistemic adverbs, like improbably and unlikely are not used in modal spread:

\#Ariadne must/may unlikely/improbably be a doctor.

The reluctance of negative modal adverbs to participate in modal spread is, to our knowledge, unnoticed in the literature - but we will argue that this restriction reveals that MUST can only convey positive bias, a fact that we will derive from our analysis in Section 4.

To see further the effect of the adverb and modal verb with negation, observe what happens when we have both: ${ }^{9}$
a. \#Dhen prepi profanos/malon na ine giatros. not must obviously/probably subj be.3 SG doctor
b. \#Non deve probabilmente/sicuramente essere un dottore. \#not must.3SG.PRES probably/certainly/forse be a doctor. 'He must not obviously/probably/maybe be a doctor.'

The addition of the modal adverb yields a bad result, as with the bare adverbs: \#Ariadne isn't probably a doctor versus Probably, Ariadne isn't a doctor. If the adverb appears above negation, as below, the result is good and forces wide scope MUST:

\footnotetext{
${ }^{8}$ Source: http: //renashall. com/wordpress / ?p=500.

${ }^{9}$ In addition, universal epistemic modal verbs and adverbs cannot appear in questions or if clauses: \#Prepi (profanos/malon) na ine giatros? \#Must it (probably, obviously) be the case that he is a doctor? For a recent description of the English facts, see Hacquard and Wellwood 2012. Our judgment above reflects these results. The Greek and Italian facts don't appear to be different. The exclusion from questions support the characterization of universal epistemic modal verbs and adverbs as PPIs (see Ernst 2009 for more discussion).
} 
a. Profanos/Malon, dhen prepi na ine giatros. obviously/probably, not must subj be.3sG doctor Obviously/probably, he must not be a doctor. (MUST $>$ NOT)

b. Probabilmente/Sicuramente, non deve essere un dottore. probably/certainly not must3SG.PRES be a doctor. 'Obviously/probably, he must not be a doctor.' (MUST>NOT)

Logically, MUST is interpreted above negation; juxtaposing the adverb outside the modal and negation interaction, allows us to see the PPI-property of both. The following puzzles, therefore, need to be addressed:

1. What is the underlying cause for positive polarity with necessity epistemic modal verbs such as prepei/dovere/must?

2. What is the underlying cause for positive polarity with modal adverbs?

3. Does the correct analysis of modal spread account for the restrictions on both modal spread and polarity?

Our discussion proceeds as follows. In Section 2, we start with the positive polarity analysis of modal adverbs, and offer some more clarifications about the modal verb and adverb combinations. We emphasize that we are not dealing with embedding, but with composition of the modal verb with the adverb. Relying on Ernst 2009, we show that the modal adverbs behave slightly differently from evaluative adverbs. In Section 3, we present the core ingredients of the modality theory we are assuming, which include: (a) the nonveridical axiom (Giannakidou 1999, Giannakidou and Mari 2016b,2018), (b) a partition in the nonveridical modal base between stereotypical and non-stereotypical worlds (c) a meta-evaluation ordering source $\mathcal{O}$ for MUST that ranks Ideal worlds as better possibilities than non-Ideal words. MUST is therefore positively biased, and we propose, in Section 4, that the adverb is the realization of $\mathcal{O}$. Our analysis bears similarities to Rubinstein 2014 and Portner and Rubinstein 2016, though these authors use secondary ordering sources. In Section 5 we addresses possibility modality. In Section 6, we show how positive bias that comes with $\mathcal{O}$, and the truth conditions of MUST force higher scoping of MUST above negation, thus deriving the PPI property. We also discuss implications and crosslinguistic predictions of our analysis. We conclude in Section 7. To our knowledge, none of the existing accounts can afford the wide coverage we offer in bridging two seemingly unrelated phenomena, PPI-hood and modal spread.

\section{Speaker-orientated adverbs and modal adverbs}

\subsection{Evaluative adverbs and modal adverbs: similarities and differences}

The positive polarity property of English modal adverbs is discussed in Nilsen 2004 and Ernst 2009, where modal adverbs are framed in the context of speaker-oriented adverbs (SOAs) including purely evaluative adverbs. The observation is that SOAs are ill-formed in the scope of a higher negation:

(27) a. Unfortunately, John disappeared.

b. Frankly, John is an idiot.

(28) a. Unfortunately, John didn't disappear.

b. \#John didn't unfortunately disappear. 
a. Frankly, John is not an idiot.

b. \#John isn't frankly an idiot.

This observation holds for a number of languages, including French, Catalan (Bonami and Godard 2008, Mayol and Castroviejo 2013), and German (Liu 2009, 2012). Recall the similarity with modal adverbs and negation we noted at the end of the previous section:

a. Profanos/Malon, dhen prepi na ine giatros.

Obviously/probably, not must subj be.3sG doctor

Obviously/probably, he must not be a doctor. (MUST>NOT)

b. Probabilmente/Sicuramente, non deve essere un dottore.

probably/certainly not must3SG.PRES be a doctor.

'Obviously/probably, he must not be a doctor.' (MUST>NOT)

Modal adverbs pattern with evaluative adverbs when it comes to the PPI property. Crucially, as PPIs, SOAs resist being in the direct scope of other nonveridical operators, e.g. questions, as illustrated in (31); Ernst also offers similar examples with luckily, happily): ${ }^{10}$
a. \#Has he unfortunately disappeared?
b. \#If he has unfortunately disappeared...
c. \#Has he surprisingly disappeared?
a. \#If he has probably disappeared...
b. \#Has he probably disappeared?
c. \#He has not probably disappeared.

Hence, modal adverbs pattern with evaluative adverbs as PPIs, but there are also differences between the two, recognized by Ernst. He distinguished between 'strong PPIs' which are blocked in all nonveridical contexts, including negation, questions and if-clauses, and 'weak' PPIs, which have a somewhat freer distribution and can be occasionally admitted in these contexts. We will only study the interaction with negation in the present paper, and will not elaborate further on the distribution. Crucially, Ernst treats modal adverbs as weak PPIs, but places evaluatives in the strong class.

One apparent difference concerns the syntactic positions of adverbs. Evaluative adverbs tend to appear in the peripheral position, either on the left or the right edge of the sentence. When they appear peripherally, they seem to have a break indicated below with the comma:
a. Unfortunately, John disappeared.
b. Unfortunately, John didn't disappear.
c. John didn't disappear, unfortunately.

In the peripheral position the negation is fine, a fact that proves the PPI property since now the adverb is outside the scope of negation. In the literature on polarity, PPI-hood is analyzed as the need to escape syntactically the offensive negation, and it typically translates into an anti-scope syntactic condition (Giannakidou 1998, Szabolcsi 2004; see also Progovac 1994). Evaluative

\footnotetext{
${ }^{10}$ PPIs exhibit limited interpretation, but are not subject to grammaticality conditions unlike NPIs (Giannakidou 2011). Consequently, a failed PPI is only infelicitous, as indicated by \# above. Metalinguistic denial (Horn 2001) can often rectify PPIs (see Ernst 2009 for discussion): John hasn't UNFORTUNATELY disappeared; I am thrilled he did!. Using \# reflects the judgement that the PPI failure is weaker than ungrammaticality - and this is an important observation about most PPIs that matters when it comes to the type of explanation needed. Finally, Liu 2012, citing earlier literature, points out occurrences of SOAs in conditionals, suggesting that the positive polarity property is mostly about the scope of negation.
} 
adverbs tend to appear precisely in the peripheral position in a number of languages including French (Bonami and Godard 2008), and in Spanish (Mayol and Castroviejo 2013) where the high scoping is understood as contributing force and expressive meaning in the sense of Potts (2007). The preference for left peripheral position is taken as evidence that the evaluative adverbs are 'appended' in the clause, and that there is a different mode of composition (e.g., expressive meaning; Mayol and Castroviejo 2013, Liu 2009, 2012).

Modal adverbs do appear in the peripheral position, as we saw; but they can also appear below the modal without intonational break, unlike evaluative adverbs:
a. O Giannis prepei mallon na ine o dholofonos the John must probably subj. be.3sG the murderer. 'John must probably be the murderer.'
b. o Giannis bori isos na ine o dholofonos. the John might maybe subj. be.3sG the murderer. 'John might perhaps be the murderer.

a. \#O Giannis prepei distixos na ine o dholofonos.

the John must unfortunately subj. be.3SG the murderer.

'\#John must unfortunately be the murderer.' (without intonational break)

Given this positioning and the contrast with evaluatives, it is impossible to argue that modal adverbs favor syntactically clause peripheral positions. A reviewer points out that there may be more nuanced cross-linguistic variation, e.g. if in some languages the post-modal position isn't available. Language specific syntax may indeed pose additional constraints. What we want to show here is that if we assume that modal adverbs are simply evaluative adverbs, we won't be able to explain why there tends to be a difference as above. Since the evaluative class has been treated compositionally as not contributing to the main assertion, we think it is worth pointing out this difference at the beginning so as to know what available analyses make sense.

Notice, in addition, that modal adverbs can appear in embedded clauses:

Credo che Maria è certamente/forse a casa.

believe.1SG.PRES that Maria is maybe/certainly at home.

I believe that Maria maybe/certainly is at home.

Pistevo oti i Maria isos/sigoura ine sto spiti.

believe.1SG.PRES that the Maria maybe/certainly is at home.

I believe that Maria maybe/certainly is at home.

If adverbs were force operators, or contributed more at the speech act level, we wouldn't expect them to embed. Importantly, adverbs can't move above the attitude verb:

\#Forse/Certamente, credo che Maria e a casa.

Maybe/certainly believe that Maria is at home.

\# Maybe, certainly, I believe that Maria is at home.

\#Isos/sigoura, pistevo oti i Maria ine sto spiti.
Maybe/certainly, believe.1SG.PRES that Maria is at home.
\#Maybe, certainly, I believe that the Maria is at home.

This shows that in the embedded position the adverbs are interpreted within the local modal structures, we take it therefore that they contribute at the sentence level, as expected since they are epistemic.

As we said, Ernst does make a distinction between modal and evaluative adverbs in terms 
of distribution, characterizing the modal ones weak PPIs. It is thus plausible to assume that, although evaluative and modal adverbs both want to avoid the scope of negation and are PPIs, they do not necessarily have to avoid the scope of negation for the same reason. A related difference between the two classes, noted in Section 1, is that the evaluative adverbs can be positive or negative (unfortunately, fortunately); but negative epistemic modal adverbs are rare (if existent at all: *un-probably, *un-maybe, *un-possibly, *un-necessarily etc.). And when possible, they can't be used with modals; recall \#Ariadne must improbably be a doctor.

As with every polarity item paradigm, one must ask the question of what makes it polarity sensitive (the 'sensitivity question', see Israel 1996, Giannakidou 2011 for an overview). Ernst offers an inspiring idea, namely that SOAs become PPIs because they are subjective. According to Ernst, subjectivity is defined as in (40), where the adverbial sentence is true in all worlds in the speaker's epistemic state M:

Subjectivity (for speaker orientation) (Ernst 2009: (62))

Where a speaker asserts $\mathrm{Q}=\mathrm{ADV}(p)$,

(a) ADV is subjective iff all the worlds by which Q is evaluated are consistent with respect to the speakers epistemic state $\mathrm{M}(\mathrm{s})$ at the time of utterance; otherwise ADV is objective.

(b) Consistency: a set of worlds ( $q$-worlds) is consistent with a belief state $\mathrm{M}$ if the proposition $q$ is true both in $q$-worlds and in all the worlds in $\mathrm{M}$.

Ernst formulates subjectivity and consistency specifically for 'speaker orientation'. Evaluative adverbs become subjectively veridical since all worlds support Q. Ernst's intent here is to indicate that the speaker is committed to the truth of the proposition when using the speaker oriented adverb. In Ernst's words: "Subjective SOAs must be true for the speaker's entire belief set - the speaker brooks no possibility of the proposition ADV(p) being false. This is how strong SOAs work, their strong emotion underlying this certitude. In contrast, evidentials are (very) objective because they necessarily invoke publicly available evidence which in principle may be at odds with the speaker's belief set. Weak PPIs are somewhere in the middle between the extremes of strong evaluative SOAs and evidentials." (Ernst 2009: 516). Modal adverbs are claimed to be weaker PPIs, and would not necessarily express such a strong certitude.

Ernst's idea is that oddity in the scope of negation arises because negation breaks the homogeneity that all worlds are $p$-worlds. The important insight of this type of account is that the PPI adverb, by getting associated with universal quantification over a set of worlds, lexically encodes a positivity that renders it incompatible with the scope of negation. Homer 2015 offers a similar account of PPI-hood of certain epistemic attitudes and modal verbs, but he does not make the connection to Ernst's work. Like Ernst, however, Homer proposes that with epistemic PPIs the modal base is homogeneous, and suggests further that this is a presupposition. Our explanation for the PPI property will use this idea- but we will show that non-homogeneity alone cannot explain PPI-hood; NPI universals, after all, are fine in the scope of negation. We will propose that the role of the adverb is crucial in producing a conflict with PPI universals.

We move on now to address more closely the empirical question of embedding, in order to make clear that in the cases under discussion in this paper we are dealing with modal composition and not embedding.

\subsection{Embedding?}

In a recent paper, Moss (2015) considers phenomena under the label 'nested epistemic vocabulary'. This term includes a variety of constructions involving multiple epistemic modal 
expressions, for which she provides a unified account. Nested epistemics include cases like (41) ((64) in Moss), with syntactic embedding.

(41) a. It is definitely the case that Bob might be the best candidate for the job.

b. It might be probable that Liem is wearing green.

Moss discusses cases of contradictory nested modals (where the modals have different forces) and non-contradictory ones (where the modals have the same force). In typical embedding as above definitely and might are of different forces, and likewise probable and might.

According to Moss, the role of the adverb is to appeal to different opinions:

$$
\llbracket \text { probably }_{i} \rrbracket^{c}=\left[\lambda S .\left\{\bigcup\left\{p \in g_{c}(i):\left.m\right|_{p} \in S\right\}>.5\right\}\right] \text { (Moss, 2015:31) }
$$

In Moss' shorthand: "find the union of everyone that accepts that $S$. If you give that proposition greater than .5 credence, then your credences are contained in the content of "probably $S^{\prime \prime}$. Moss concludes that the sentence in (35) means that, according to all (because of definitely) credences it is possible that Bob is the best candidate for the job.

Moss' view, it seems to us, correctly acknowledges a semantic role for the adverbs, but we see no empirical motivation for additional assumptions such as the internal committee representing sets of worlds in which different credences hold. We will cast our analysis in the more widely used semantics of Kratzer and Portner, and will make additional assumptions only if they are motivated empirically within that system.

Moreover, Moss's account is not designed to address the adverbs in connection to their polarity properties, and does not discuss the interaction with negation at all. A theory is needed that derives the difference between modal spread and embedding, while tolerating a certain degree of flexibility for the observed co-occurrences of differing forces with modal spread in Italian noted earlier.

We think that modal embedding is real, and it is to be distinguished from modal spread. The study of nested modals, to use Moss' term, only recently attracted attention; it is therefore progress to state that 'nesting' is in fact two phenomena: spread (which involves one modal operator) and embedding (which involves two or more).

To conclude, an evaluative analysis does not seem attractive for modal adverbs. We retain Ernst's idea of positivity as universal quantification in a set of worlds, and create a system that is similar to using multiple ordering sources (Rubinstein, 2014). Let us proceed now with the theory of modality we will rely on.

\section{Epistemic necessity, (non)veridicality, and truth}

The foundation of our analysis will be the Kratzer semantics for modality, where modal verbs take modal bases and ordering sources. Following Giannakidou 1998, 1999, 2013b, Mari 2015,2017 and Giannakidou and Mari 2012a, b, 2013, 2016b, we will add the 'Nonveridicality Axiom' that all modal bases are nonveridical, i.e. they are non-homogenous spaces containing $p$ and $\neg p$ worlds. Beaver and Frazee 2016 adopt nonveridicality as a defining property of modality, and the Nonverdicality axiom appears in Condoravdi 2002 as a 'diversity' condition for modal bases. Nonveridicality derives a semantics of universal modals as 'weak', i.e., not entailing (knowledge of) the prejacent $p$, in the tradition of the 'mantra' (labelled so by von Fintel and Gillies 2010). We newly propose here that necessity modals express additionally 'positive bias', and this bias is responsible for positive polarity. 


\subsection{Subjective (non)veridicality: truth assessment relying on knowledge}

In extensional contexts, sentences are assigned a truth value by a valuation function, and are true or false in the actual world. While this may be adequate for textbook purposes, it soon becomes obvious that assessing truth is not simply a matter of assignment; rather, speakers form judgements about the veridicality of a sentence, and as such the veridicality judgement is more complex. Truth is judged relative to a speaker and a hearer, who assess whether a sentence is true or not given what they know or what they believe (Giannakidou 1994, 1998, 1999, 2009, 2013b; Harris and Potts 2009; de Marneffe et al. 2012; Mari 2015c on perspectival generics). That such relativization is needed becomes particularly visible with propositional attitude verbs (know, believe, imagine, etc) and their complements (Farkas 1985, Giannakidou 1994, 1998, Mari 2016b, Giannakidou and Mari 2016a); but the role of the individual in assessing truth is apparent even in unembedded sentences, as expressed lucidly in Harris and Potts' assertion that all sentences are perspectival.

When a speaker asserts a positive unmodalized sentence in the present or past, unless she is lying, she asserts $p$ because she knows or believes that $p$ is true; ${ }^{11}$ but when a speaker uses a modal verb, she may think that $p$ is possible or even likely, she may have evidence supporting that $p$ is true, but she doesn't know for sure that $p$ is true. When speakers make assertions or assess assertions of others, they make veridicality judgments about the truth of the sentenceand the veridicality judgement, as we said, is more complex than truth assignment: it depends on what speakers know and how they extract information from context (see especially Giannakidou 1998, 2013a, Mari 2003,2005, Giannakidou and Mari 2016b; de Marneffe et al. 2012 confirm this complexity with corpus data).

It makes sense, then, to talk about objective and relative veridicality for all sentences. Objective veridicality depends on what is the case or not in the world, and corresponds to actual truth; but in relative, or subjective, veridicality, an individual is making the judgement, and becomes the individual anchor (Farkas 1992, Giannakidou 1994, 1998, et sequ.). The veridicality judgment relies on what the anchor knows or believes to be the case. ${ }^{12}$ For unembedded sentences, the individual anchor is always the speaker. For an unmodalized assertion of $p, p$ is assertable only if the speaker knows or at least believes $p$ to be true. In other terms, veridicality is a condition on the speech act of assertion. Another way to phrase this is to say that the speaker is epistemically committed to $p$. If the speaker doesn't know or believe $p$, she is said to not be epistemically committed to $p$ (see also Smirnova 2013). Moore paradoxical sentences \#p and I do not believe that $p$ are infelicitous because the assertion of $p$ says that the speaker knows or believes $p$ to be true, and then she goes on to deny that (for more recent discussion, see Lauer, 2013; Giannakidou and Mari 2016b, Mari, 2018).

Giannakidou $(1994,1997)$ was among the first to propose a generalization of the veridicality judgement relative to individual anchors $i$ and their epistemic states. In main clauses the anchor is by default the speaker. ${ }^{13}$ 'Models of evaluation' are defined to describe the information states of anchors (see Giannakidou 2013 for updated discussion). These models are sets of worlds, relative to $i$, corresponding to what $i$ believes or knows. ${ }^{14}$ Following Giannakidou 1999: (45),

\footnotetext{
${ }^{11}$ The relation between assertion and belief is complex, and currently under close scrutiny (see Lauer 2013; Krifka 2015; Mari 2017b). We do not enter this debate here, and focus on modality rather than belief.

${ }^{12}$ With sentences containing predicates of personal taste (Lasersohn 2005; Stephenson 2007) veridicality is determined not by knowledge but by taste or experience, and the individual anchor is called the judge.

${ }^{13}$ Individual anchoring of truth should be seen on a par with other kinds of anchoring of propositional content, i.e. temporal anchoring, or event anchoring (e.g. Hacquard 2006, 2010).

${ }^{14}$ The difference between knowledge and belief is not important here, and in many other cases, e.g. for mood choice, it doesn't matter either- - as verbs of knowledge and belief both select the indicative in many languages.
} 
2013, we call these models epistemic states in our definition below:

\section{Epistemic state of an individual anchor $i$}

An epistemic state $\mathbf{M}(i)$ is a set of worlds associated with an individual $i$ representing worlds compatible with what $i$ knows or believes in the context of utterance.

$\mathrm{M}(i)$ is a non-trivial set that encompasses $i$ 's beliefs and knowledge about the world. Given $\mathrm{M}(i)$, we identify (non)veridicality subjectively as inference to $i$ knowing or believing $p$ :

\section{Subjective veridicality (for functions)}

A function $\mathrm{F}$ that takes a proposition $p$ as its argument is subjectively veridical with respect to an individual anchor $i$ and an epistemic state $\mathrm{M}(i)$ iff $F p$ entails that $i$ knows or believes $p$ : i.e., iff $\forall w^{\prime}\left[w^{\prime} \in \mathbf{M}(i) \rightarrow p\left(w^{\prime}\right)\right]$.

Subjective veridicality reflects knowledge or belief of $i$ that $p$ is true, as in the classical treatment of Hintikka (1962), and implies 'homogeneity' of the entire M $(i)$.

Veridical functions require that the individual anchor is in an epistemic state that supports $p$, regardless of whether $p$ is actually (i.e. objectively) true. For instance, Nicholas believes that Ariadne is a doctor reflects a veridical epistemic state (with respect to Nicholas $=i$ and Nicholas's belief state $=\mathrm{M}(i)$, but the sentence Ariadne is a doctor can be objectively false.

$\llbracket$ Nicholas believes that $p \rrbracket$ is true in the world of the utterance context $w$ iff: $\forall w^{\prime}\left[w^{\prime} \in \operatorname{Dox}(\right.$ Nicholas,$\left.w) \rightarrow p\left(w^{\prime}\right)\right]$

The truth condition of believe does not entail actual truth. However, (45) renders believe subjectively veridical, because the whole $\mathbf{M}($ Nicholas $)$ supports $p$, that it is to say, $\mathbf{M}$ (Nicholas) entails $p$.

When all worlds in $\mathbf{M}(i)$ are $p$ worlds, $p$ is entailed in $\mathbf{M}(i)$. This is a state of full epistemic commitment to $p$, a homogenous $p$-space. The verb know prototypically reflects such a homogenous veridical epistemic state. Other verbs denoting private epistemic spaces such as dream, imagine ${ }^{15}$ are subjectively veridical like believe: they fully support $p$, but unlike know they do not entail actual truth (Giannakidou 1994, 1998, 1999; Giannakidou and Mari 2016a,b).

For unembedded sentences, subjective veridicality is a condition ${ }^{16}$ on assertability:

$$
\begin{aligned}
& \text { Flavio is a doctor is assertable by speaker } i \text { if and only if } \\
& \forall w^{\prime}\left[w^{\prime} \in \mathbf{M}(i) \rightarrow \text { doctor }(\text { Flavio })\left(w^{\prime}\right)\right] \text {. }
\end{aligned}
$$

An unmodalized unembedded sentence expresses the speaker's belief or knowledge of $p$. A negative sentence, in a parallel manner, expresses the speaker's belief or knowledge that not $p$ :

Giacomo is not a doctor is assertable by speaker $i$ of and only if

$$
\forall w^{\prime}\left[w^{\prime} \in \mathbf{M}(i) \rightarrow \neg \operatorname{doctor}(\text { Giacomo })\left(w^{\prime}\right)\right] \text {. }
$$

Again we have a universal condition, this time that all worlds in $\mathrm{M}(i)$ be $\neg p$ worlds. We can therefore say that unmodalized sentences, positive or negative, are epistemically settled in the

Mari 2016 refines the typology of non-epistemic and fictional attitudes by showing that there is a systematic ambiguity between expressive-belief (the classical Hintikkean belief) and inquisitive-belief (which triggers subjunctive in languages in which mood is parametric to the status of $p$ in the common ground). Inquisitive belief thus expresses epistemic uncertainty in some languages. Here, we only focus on Hintikkean belief which presupposes subjective veridicality.

${ }^{15}$ See footnote 8 and Mari, 2016,2017 for a refinement of the meaning of fictional attitudes.

${ }^{16}$ It is still unclear whether necessary and/or sufficient, see discussion in Mari, $2017 \mathrm{~b}$. 
modal space $\mathbf{M}(i)$, where $i$ is the speaker:

$$
\begin{aligned}
& \text { Epistemic settledness in } \mathbf{M}(i) \\
& \mathbf{M}(i) \text { is epistemically settled about } p \text { iff }\left(\forall w^{\prime} \in \mathbf{M}(i) p\left(w^{\prime}\right)\right) \vee\left(\forall w^{\prime} \in \mathbf{M}(i) \neg p\left(w^{\prime}\right)\right)
\end{aligned}
$$

The notion of epistemic settledness is useful as a characterization of homogeneity, and it includes both veridicality (all worlds are $p$ worlds, the epistemic state is positively settled) and antiveridicality (all worlds are $\neg p$ worlds, the epistemic state is negatively settled). When $p$ is positively settled in $\mathrm{M}(i), i$ is said to be fully committed to $p$; when $p$ is negatively settled in $\mathrm{M}(i), i$ is said to not be committed to $p$, i.e. to reject $p$.

We can now define veridicality and antiveridicality as properties of epistemic states as follows:

\section{Veridicality of epistemic states}

a. An epistemic state $\mathrm{M}(i)$ is veridical about $p$ iff it is positively settled: i.e $\forall w^{\prime} \in \mathbf{M}(i): p\left(w^{\prime}\right)$

b. An epistemic state $\mathrm{M}(i)$ is antiveridical about $p$ iff it is negatively settled: i.e $\forall w^{\prime} \in \mathbf{M}(i): \neg p\left(w^{\prime}\right)$

Nonveridicality, on the other hand, is a property of a function that does not entail that $i$ knows or believes $p$ to be true; in terms of epistemic states, nonveridicality is defined as in (51).

\section{Subjective nonveridicality (for functions)}

A function $\mathrm{F}$ that takes a proposition $p$ as its argument is subjectively nonveridical with respect to an individual anchor $i$ and an epistemic state $\mathrm{M}(i)$ iff $F p$ does not entail that $i$ knows or believes $p$ : i.e., iff $\exists w^{\prime} \in \mathbf{M}(i) p\left(w^{\prime}\right) \& \exists w^{\prime \prime} \in \mathbf{M}(i) \neg p\left(w^{\prime}\right)$.

\section{Nonveridical epistemic state}

An epistemic state $\mathrm{M}(i)$ is nonveridical about $p$ iff $\mathrm{M}(i)$ contains both $p$ and $\neg p$ worlds.

Nonveridical epistemic states $\mathrm{M}(i)$ are non-homogenous, containing $p$ and $\neg p$ worlds. They are therefore, also, epistemically unsettled. Inquisitive spaces such as questions are, according to Giannakidou 1997, 1998, 2013, prototypical nonveridical epistemic states. Statements with possibility modals and modals generally are also nonveridical (labelled 'inquisitive assertions' by Giannakidou 2013), and epistemically weaker (Giannakidou and Mari 2016b) than unmodalized assertions: It is raining and $I$ believe that it is raining are stronger epistemically than It must be raining because they are not partitioned. We give more details on this point in the next section.

Following Giannakidou and Mari 2016b, 2018, we formulate nonveridicality as a precondition on modalities in the form of the axiom below:

\section{Nonveridicality Axiom of modals}

MODAL (M) ( $p$ ) can be defined if and only if the modal base $\mathrm{M}$ is nonveridical, i.e. only if M contains $p$ and $\neg p$ worlds.

The nonveridicality axiom requires that the modal base $\mathrm{M}(i)$ be partitioned into worlds where $p$ is true, and worlds where $p$ is not true. This idea, as we mentioned at the beginning of this section, was also present in Condoravdi's 2002 diversity condition. Non-aleithic modals (possibility and necessity, epistemic, deontic, bouletic, etc) obey this principle, and therefore come with partitioned modal bases; consequently, epistemic modals do not entail $p$ or knowledge of the speaker that $p$, and express, as Giannakidou and Mari 2016b put it (see also Giannakidou 
2013), reduced commitment to $p \cdot{ }^{17}$ Unmodalized assertions express full commitment, and are therefore stronger than modalized sentences.

To summarize, we end up with the following typology of modal spaces (sets of worlds):
Veridical and nonveridical modal spaces, homogeneity
a. A modal space $\mathrm{M}$ is veridical with respect to a proposition $p$ iff it is positively homogenous: $\forall w^{\prime}\left(w^{\prime} \in M \rightarrow p\left(w^{\prime}\right)\right)$
b. A modal space $\mathrm{M}$ is nonveridical with respect to a proposition $p$ iff it is non- homogenous: $\exists w^{\prime}, w^{\prime \prime} \in M\left(w^{\prime} \neq w^{\prime \prime} \wedge\left(p\left(w^{\prime}\right) \wedge \neg p\left(w^{\prime \prime}\right)\right)\right.$
c. A modal space $\mathrm{M}$ is antiveridical with respect to a proposition $p$ iff it is negatively homogenous: $\forall w^{\prime}\left(w^{\prime} \in M \rightarrow \neg p\left(w^{\prime}\right)\right)$

There are all sorts of modal spaces corresponding to all sorts of modalities and propositional attitudes, and the above definitions are general enough to be used broadly. In the rest of the paper, we focus on epistemic modals.

\subsection{Epistemic MUST: nonveridicality and weak necessity}

\subsubsection{Partition in the modal base}

Giannakidou and Mari (2016b,2018) adopt the analysis of must by Kratzer 1991 (also Giorgi and Pianesi 1997, Portner 2009). MUST (and specifically Italian dovere and Greek prepi), associates with an epistemic modal base $\mathrm{M}(i)$ which is the set of propositions known by the speaker $i$ at $t_{u}$ (the utterance time). $w_{0}$ is the world of evaluation, by default the actual world:

$$
\mathbf{M}(i)\left(t_{u}\right)\left(w_{0}\right)=\lambda w^{\prime}\left(w^{\prime} \text { is compatible with what is known by the speaker } i \text { in } w_{0} \text { at } t_{u}\right)^{18}
$$

The epistemic modality is by default 'subjective' (Lyons 1977), and knowledge changes with time. Epistemic modality is therefore parametric to knowledge at $t_{u}$, as is often acknowledged in the literature (see Portner 2009, Hacquard 2006,2010, Giannakidou and Mari 2016b).

Given what the speaker knows, the modal base of epistemic MUST is nonveridical about the proposition $p$ denoted by its prejacent, and contains both $p$ and $\neg p$ worlds. To derive the truth conditions of MUST we assume with the literature (see e.g. Portner, 2009) that MUST uses a set of propositions $\mathcal{S}$ which describe shared stereotypical/normalcy conditions. Such conditions have most notably been discussed in relation to genericity (see Asher and Morreau 1995), progressives (Dowty 1979; Landman 1992; Portner 1998), but appear also as inertia (Dowty, ibid.), stereotypicality (Portner, 2009), and reasonability (Landman ibid., Portner 1998; Mari 2014; see also discussion in Mari, Beyssade and Del Prete, 2012).

The Kratzer/Portner semantics posits an ordering source Best which ranks worlds according to how close they are to the stereotypical ideal. Our account encodes that the modal base is partitioned into stereotypical and non-stereotypical worlds, but we dissociate stereotypicality from ranking. This allows us to capture possibility modals as undergoing the initial partition

\footnotetext{
${ }^{17}$ There are two exceptions to the axiom, and both result in trivialization of modality. The first case is the actuality entailment of ability modals, where the modal is trivialized (see Mari 2017). The second case is aleithic modality, as in $1+1$ must equal 2. Giannakidou and Mari (2016b) distinguish this aleithic must from the epistemic use - thus maintaining nonveridicality and so-called 'weakness' of epistemic MUST (Karttunen (1972). With both aleithic modality and actuality entailment, the distinction between modal and non modal statement is lost.

${ }^{18}$ It should be clear that our notation $\mathrm{M}(i)$ corresponds to the Kratzerian notation using set intersection $\cap f_{\text {epistemic }}\left(w_{0}, i, t_{u}\right)$, where this returns the set of worlds compatible with what it is known in $w_{0}$ by $i$. It is also clear that modality, in our framework, is always subjective, allowing also for cases where $i$ is a collective individual or group of people to capture what others would call objective modality.
} 
between stereotypical and non-stereotypical worlds without necessary ordering. Ranking in our system is expressed via a meta-evaluation which ranks the two sets of worlds produced by the initial partition. The adverb is the manifestation of the ranking, we will argue.

In the epistemic modal base $\mathbf{M}(i)\left(t_{u}\right)\left(w_{0}\right)$, we define $\operatorname{Ideal}_{\mathcal{S}}$ as a function over $\mathbf{M}(i)\left(t_{u}\right)\left(w_{0}\right)$, still in the spirit of Portner 2009. The output $\operatorname{Ideal}_{\mathcal{S}}$ is a subset of $\mathbf{M}(i)\left(t_{u}\right)\left(w_{0}\right)$ :

$$
\operatorname{Ideal}_{\mathcal{S}}\left(\mathbf{M}(i)\left(t_{u}\right)\left(w_{0}\right)\right)=\left\{w^{\prime} \in \mathbf{M}(i)\left(t_{u}\right)\left(w_{0}\right): \forall q \in \mathcal{S}\left(w^{\prime} \in q\right)\right\}
$$

So defined, Ideal $_{\mathcal{S}}$ delivers the worlds in the epistemic modal base in which all the propositions in $\mathcal{S}$ are true. $\mathcal{S}$ is a set of propositions that corresponds to common ground norms. ${ }^{19}$ The set Ideal $_{\mathcal{S}}$ is also parametric to time. Unless otherwise stated, we consider that Ideal $_{\mathcal{S}}$ is determined at actual world and at the utterance time (this will be indeed always the case in the reminder of the paper). As we can see, there is no ranking.

Let us consider now the weakness of MUST. For von Fintel and Gillies, like for Karttunen 1972 before them, must requires the evidence for the prejacent $p$ to be indirect. In the framework we outlined, the issue is not about directness or indirectness, but of knowledge: when a speaker uses MUST, she doesn't know that $p$ is true. If the speaker knows that $p$ is true, she will not modalize. As argued in Giannakidou and Mari 2016b, by using MUST the speaker indicates reduced commitment to the truth of $p$. To understand why this is a better way of understanding MUST, consider visual and auditory evidence. Von Fintel and Gillies predict both to be incompatible with MUST because they are both direct, but we predict a difference between seeing and hearing the rain. Consider seeing first, which is the well known case. MUST is infelicitous when I see, therefore I know, that it is raining.

Context: I am in my office, looking at the rain through the window. I say: \#It must be raining.

For von Fintel and Gillies, echoing Karttunen, the example is odd because evidence is not indirect; for us, the sentence is odd because if I see the rain I know it is raining. Now, consider what happens if I only hear the rain. In this context, contrary to seeing the rain, MUST is fine:

Context: I am in a room, no windows; I hear sounds of what could be rain. I say:
a. It must be raining.
b. Prepi na vrexi.
must subjunctive raining.
c. Pioverà.
rain-FUT.3sg.
d. Tha prepi na vrexi.
FUT must subjunctive rain.

I only have sound that supports inferencing that it is raining (but it could be my neighbor watering the grass with a loud device). Hearing $p$ is direct evidence, but does not license knowledge of $p$, and MUST becomes good. Since hearing is as direct as seeing (wee Willett 1988 upon whom von Fintel and Gilles 2010 rely), the contrast above is not predicted by von Fintel and Gillies who expect MUST to be infelicitous with hearing too. Therefore, Giannakidou and Mari 2016b conclude, inferencing with MUST is about what $i$ knows and not about directness or indirectness. MUST indicates that the speaker is not fully committed to the truth of $p$, and has only partial knowledge that supports the prejacent. Epistemic MUST, therefore, requires

\footnotetext{
${ }^{19}$ Since only those worlds are considered in which all the propositions in $\mathcal{S}$ are true, the function Ideal $_{\mathcal{S}}$ determines a cut-off point.
} 
inferential gaps.

The conclusion that MUST requires partial knowledge is supported consistently by the data (in all three languages we are discussing). Consider now the following scenario:

Context: I see a wet umbrella.

It must be raining.

If I only see a person coming in with a wet umbrella, I do not know that it is raining, but I can infer, given the partial information I have, that it must be. MUST is felicitous in this inferential context because seeing a wet umbrella alone is not full information that it is raining, it therefore does not imply that I know that it is raining. There is an epistemic gap, like in the hearing case, that allows me to infer, but not know for sure, that it is raining.

Consider further the observation that MUST statements can be continued by 'but I am not entirely sure', in Italian and Greek, as first noted in Bertinetto 1979; Mari 2009a,b, Giannakidou and Mari 2012b; see extended discussion in Giannakidou and Mari 2016b where the following example is drawn from:

$$
\begin{aligned}
& \text { Deve essere a casa, ma non sono totalmente sicuro. } \\
& \text { Must.3SG.PRES be at home, but not be.1SG.PRES entirely sure. } \\
& \text { 'He must be home, but I am not entirely sure.' }
\end{aligned}
$$

In this respect, MUST differs from know and the bare positive assertion which are veridical, and does not accept such continuation:

a. \#He is at home but I am not entirely sure.

b. \#I know he is at home but I am not entirely sure.

Comparing unmodalized assertions with modalized sentences, Giannakidou and Mari 2016b posit a scale of epistemic commitment, where the unembedded assertion which implies knowledge or belief of $p$ expresses the highest commitment. Modal verbs produce epistemic weakening, which means that they express weaker commitment to $p$. MUST expresses partial commitment, and the possibility modal expresses the weakest commitment of simply raising (or, not excluding) the possibility of $p$ (called neutral commitment below):

$$
\begin{aligned}
& \text { Scale of epistemic commitment (Giannakidou and Mari 2016b) } \\
& <p \text {, MUST } p \text {, MIGHT } p>\text {; } \\
& \text { where } p \text { conveys full commitment of } i \text { to } p \text {; MUST } p \text { conveys partial commitment, and } \\
& \text { MIGHT } p \text { conveys neutral commitment. }
\end{aligned}
$$

The criterion for epistemic commitment is (non)veridicality, i.e., $p$, MUST $p$, and MIGHT $p$ are ranked based on veridicality: full commitment corresponds to a veridical $\mathrm{M}(i)$, and reduced commitment (partial, as well as neutral) to nonveridical M $(i)$. MUST $p$ is stronger than MIGHT $p$ because it supports $p$ in the Ideal worlds (cf. infra), and MUST has positive bias as we make precise next. The degree of commitment, finally, correlates also with how informative the sentence is (see further Giannakidou 2013, and Giannakidou and Mari 2016b). MUST does not express full commitment to $p$, but expresses partial commitment towards the prejacent.

Lassiter 2016 offers numerous attested examples supporting our view of MUST, where must is compatible with 'I don't know for sure', and similar expressions challenging knowledge of $p$ :

(62) This is a very early, very correct Mustang that has been in a private collection for a long time. ... The speedo[meter] shows 38,000 miles and it must be 138,000, but I 
don't know for sure.

(63) I don't know for sure, sweetie, but she must have been very depressed. A person doesn't do something like that lightly.

(64) It must have been a Tuesday (but I don't know for sure), I can't remember"

(65) I have an injected TB42 turbo and don't like the current setup. There is an extra injected located in the piping from the throttle body... Must be an old DTS diesel setup but I'm not certain. Why would they have added this extra injector?

There is nothing about indirectness here; the examples support the nonveridicality of MUST, i.e. that it cannot entail knowledge of, therefore full commitment to, $p$. MUST, rather, is inferential - signaling inference to $p$ based on a number of premises and potential gaps.

Consider, finally, deductive contexts:

(66) The ball is either in A, B or C. It is neither in A nor in B. It must be in C.

In this case, MUST indeed entails $p$ and that the speaker knows $p$. But does this show that MUST is strong, as von Fintel Gillies would have it? Giannakidou and Mari 2016b argue that MUST in this case is not epistemic but aleithic. Crucially, in the context above, the speaker has all the knowledge available, there are not gaps - unlike with epistemic MUST. Aleithic MUST can bear focus, unlike epistemic i MUST which is does not. Consider how odd it is in the inferential context to focus must:

Context: I see a wet umbrella.

\# It MUST be raining.

\# PREPI na vrexi.

(68) The ball is either in A, B or C.

a. The ball is neither in A nor in B. It MUST be in C.

b. Dhen ine sto A oute sto B, ara PREPI na ine sto C. (Greek)

c. La palla è in A o in B. Non è né in A, né in B. DEVE essere in C. (Italian)

It is therefore reasonable to be cautious about the aleithic use of MUST, and not confuse it with epistemic MUST which obeys the nonveridicality axiom and relies on inference and partial knowledge (Giannakidou and Mari, 2016b).

Epistemic MUST, summarizing, has the following basic truth condition requiring that $p$ is true in the Ideal set of $\mathrm{M}(i)$. Tense comes from below (a semantic present or past; see Giannakidou and Mari, 2018 for discussion of tense); recall that $t_{u}$ is the utterance time. From now on, we assume that, by default, $\mathrm{M}(i)$ is projected at the time of utterance in the actual world. Given a set Ideal $_{\mathcal{S}}$ and the utterance time $t_{u}$,

(70) (to be completed)

(to be completed)

$\llbracket$ prepi/devere/must $(\operatorname{PAST}(p)) \rrbracket^{M, i, \mathcal{S}}$ is defined only if $\mathrm{M}(i)$ is nonveridical and is partitioned into Ideal $_{\mathcal{S}}$ and $\neg$ Ideal $_{\mathcal{S}}$ worlds. If defined,

$\llbracket$ prepi/devere/must $(\operatorname{PAST}(p)) \rrbracket^{M, i, \mathcal{S}}=1$ iff $\forall w^{\prime} \in \operatorname{Ideal}_{\mathcal{S}}: \exists t^{\prime} \prec t_{u} \wedge p\left(w^{\prime}, t^{\prime}\right)$

$\llbracket$ prepi/devere/must (PRES $(p)) \rrbracket^{M, i, \mathcal{S}}$ is defined only if $\mathrm{M}(i)$ is nonveridical and is partitioned into Ideal $_{\mathcal{S}}$ and $\neg$ Ideal $_{\mathcal{S}}$ worlds. If defined,

$\llbracket$ prepi/devere/must $(\operatorname{PRES}(p)) \rrbracket^{M, i, \mathcal{S}}=1$ iff $\forall w^{\prime} \in \operatorname{Ideal}_{\mathcal{S}}: p\left(w^{\prime}, t_{u}\right)$

Echoing Giannakidou and Mari 2016b (and Szabo and Knobe 2013 before them), we can think 
of Ideal $_{\mathcal{S}}$ as the 'inner' domain of MUST, and M( $\left.i\right)$ as the 'outer' domain. The outer domain is a nonveridical space with respect to $p$, but Ideal ${ }_{\mathcal{S}}$ is veridical: all worlds are $p$ worlds. This accounts for the illusion of strength. And there exists an additional component, that we proceed to study next, which is responsible for positive polarity.

\subsubsection{Positive bias and meta-evaluating ordering source}

We will now postulate that $\operatorname{Ideal}_{\mathcal{S}}$ and $\neg \mathrm{Ideal}_{\mathcal{S}}$ worlds are ranked according to an ordering source $\mathcal{O}$. It is common to assume secondary ordering sources in recent literature (von Fintel and Iatridou, 2008; Rubinstein 2014, Portner and Rubinstein 2016); but given that our initial partitioning into Ideal $_{\mathcal{S}}$ and non-Ideal $\mathcal{S}_{\mathcal{S}}$ worlds does not depend on ranking, $\mathcal{O}$ is not a secondary ordering. It is the primary ordering source, a 'meta-evaluation' that compares $\operatorname{Ideal}_{\mathcal{S}}$ to its complement in $\mathrm{M}(i)$ (we thank Paul Portner for suggesting this term). Before we consider how ideality and stereotypicality specifically for epistemic modals, let us say more about the relation between ideality and metaevaluation.

In everyday life, we constantly evaluate whether the actual world follows stereotypical rules. What counts as normal or reasonable outcome depends on one's knowledge and experience, and human agents make use of expectations relying on knowledge and experience when they reason. Normalcy and reasonability manifest themselves as domain restriction with quantifiers, or ignoring exceptions with generic statements, to mention just two well known examples. Of course, actual outcomes do not always conform to what is expected under normalcy conditions, and expectation of not conforming to what it is 'normal' determines often our uncertainty (besides not having complete knowledge). We propose the meta-evaluation $\mathcal{O}$ as a way to capture the speaker's confidence in normalcy effects. $\mathcal{O}$ contains those propositions that allow $i$ to evaluate the relative ranking of stereotypical as better possibilities than non-stereotypical worlds.

Consider the case of John who is invited to a party. He is leaving from Place de la Sorbonne and needs to reach the Louvre. We know that he takes the metro. We also know that usually the metro works well in Paris. Ideal ${ }_{\mathcal{S}}$ creates a partition is $\mathrm{M}(i)$ in which John arrives on time (these are worlds in which the metro worked well) and worlds in which he does not arrive on time (these are worlds in which the metro breaks down). Now, how likely are the worlds in which John arrives on time in comparison with those in which he does not? Usually, we believe, they are very likely, one of the propositions in $\mathcal{O}$ being 'I trust the metro system more than the car.' Stated otherwise, stereotypicality triggers high confidence in (thus more commitment to) one's conclusion, and this seems to be something basic about the way humans draw conclusions. One will have a tendency to rank the stereotypical worlds as more reliable than the non-stereotypical ones. In this case one would probably utter something like (71-a) or even (71-b).

a. John must be at the Louvre.

b. John must definitely be at the Louvre.

As we explained, higher ranking of stereotypical worlds is a common practice across individual anchors, who evaluate stereotypical worlds higher over non-stereotypical ones. Some anchors, however, can evaluate the situation in a different manner. Based on their pessimistic personal inclinations, or convinced that public transportation is not as unreliable as expected, one can draw a different conclusion. $\mathcal{O}$ will be different in this case, including 'I do not trust the metro system.' In this case, in a language like Italian, one would probably utter something like the following sentence, where the MUST combines with a possibility modal:

Deve forse essere al Louvre.

Must maybe be at the Louvre. 
A few comments. First, as we have noted, there is a pragmatic dependency between stereotypicality and the ordering source $\mathcal{O}$, revealing trust in the normalcy conditions. This dependency can be fragile because $\mathcal{O}$ is subjective, and does not rely on shared rules like the initial Ideal $_{\mathcal{S}}$ partition. $\mathcal{O}$ is a negotiable (Rubinstein, 2014, Portner and Rubinstein 2016) meta-evaluation of how confident $i$ is about $\operatorname{Ideal}_{\mathcal{S}}$ being a better possibility than $\neg \operatorname{Ideal}_{\mathcal{S}}$. In this sense, $\mathcal{O}$ can change as more arguments are added in the conversation.

Second, languages differ in the strength of the meta-evaluation. Languages like Greek maintain a dependence between stereotypicality and the metaevaluation; recall that there is no Greek counterpart of (72). ${ }^{20}$ In other languages, the pragmatic connection between stereotypicality and $\mathcal{O}$ is more fragile, and $\mathcal{O}$ can reveal a low confidence, as we explain in Section 6.2.

Third, and most importantly, lexical items encode whether $\mathcal{O}$ is empty or not, that it is to say, whether stereotypicality triggers ordering or not. MUST, we claim, lexically encodes a default preference for a non-empty $\mathcal{O}$, but epistemic possibility tends to encode an empty one. Note that, both epistemic necessity and possibility have a non-empty $\mathcal{S}$. As we shall see in Section 6.2 , these lexical tendencies can be overwritten and languages differ in the extent to which they allow overwriting.

Let us now consider further how ideality and stereotypicality interact with epistemic modals

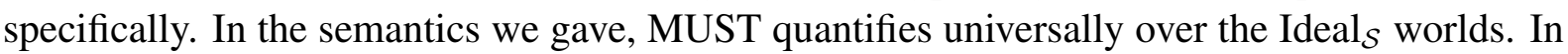
the specific case of the positive assertion, all $\mathrm{Ideal}_{\mathcal{S}}$ worlds are $p$ worlds. $\mathcal{O}$, in addition, reveals $i$ confidence towards the prejacent; it does so indirectly by determining an ordering between the Ideal $_{\mathcal{S}}$ worlds where the prejacent is true and $\neg$ Ideal $_{\mathcal{S}}$ worlds. With universal epistemic modals, $\mathcal{O}$ ranks Ideal $_{\mathcal{S}}$ worlds as better possibilities than $\neg \operatorname{Ideal}_{\mathcal{S}}$ worlds. We encode this below as positive bias:

Positive bias of epistemic necessity modals.

$\mathrm{Ideal}_{\mathcal{S}}$ is a better possibility than $\neg \mathrm{Ideal}_{\mathcal{S}}$, relative to $\mathrm{M}(i)$ and $\mathcal{O}$.

According to (73), there is no $\neg \mathrm{Ideal}_{\mathcal{S}}$ world in $\mathrm{M}(i)$ which is not outranked by an $\mathrm{Ideal}_{\mathcal{S}}$ world. And since, by the truth condition of MUST, all ideal worlds are worlds in which the prejacent is true, $\mathcal{O}$ is responsible not just for positive bias towards $\operatorname{Ideal}_{\mathcal{S}}$, but also towards the prejacent itself.

Also, note that (73) states that worlds that are compatible with what the speaker knows in the actual world $w_{0}$ (recall that $\mathbf{M}(i)$ is projected from the actual world) are ideal and thus better ranked. Hence, according to the speaker, the actual world is more likely be a world where the prejacent is true.

We can now build on the connection between weak necessity and better possibility (see Portner, 2009:70), we restate (73) as in (74).

$$
\begin{aligned}
& \text { Positive bias of epistemic necessity modals (final). } \\
& \text { Ideal }_{\mathcal{S}} \text { is weak necessity with respect to } \neg \mathrm{Ideal}_{\mathcal{S}} \text {, relative to } \mathrm{M}(i) \text { and } \mathcal{O} \text {. }
\end{aligned}
$$

As we noted earlier, authors have generally acknowledged a need to 'discriminate' between the two options in the modal base with necessity modals (e.g. Rubinstein 2014, Portner and Rubinstein 2016). Our own implementation proceeds in two steps, determining a partition based on stereotypicality and then evaluating the relative ranking of the two subsets. And recall again that the preference for Ideal $_{\mathcal{S}}$ relies on a (potentially fragile) connection between stereotypicality and confidence of $i$ that the actual world behaves in a stereotypical way.

Existential modals are generally taken to not have ordering sources (although there is vari-

\footnotetext{
${ }^{20}$ Recall from Section 1 that English has a flexibility similar to the one observed for Italian.
} 
ation across types of existential modals, see discussion in Portner, 2009). We will assume following most of the literature that epistemic possibility modals come with an empty $\mathcal{O}$, and we will call this, following our earlier work, nonveridical equilibrium Section 5 offers more discussion, and in Section 6.2, we see that the default preference for non-empty ordering sources can be overwritten.

As noted already, since Ideal $_{\mathcal{S}}$ is the set of worlds in which the prejacent is true, in ranking the $\operatorname{Ideal}_{\mathcal{S}}$ worlds as higher as the $\neg \mathrm{Ideal}_{\mathcal{S}}, \mathcal{O}$ reveals $i$ 's confidence that the prejacent is true. Recall that MUST does not convey full commitment: its modal base is nonveridical. However, it conveys partial commitment, and the set Ideal $_{\mathcal{S}}$ in which the prejacent is true is ranked as higher by $\mathcal{O}$. In order to successfully convey partial commitment towards the prejacent, the Ideal $_{\mathcal{S}}$ set must be homogeneous and contain only those worlds in which the prejacent is true. Indeed, if the $\operatorname{Ideal}_{\mathcal{S}}$ set were not homogeneous, the sentence would convey that the speaker is equally committed towards the prejacent and its negation and the sentence would become uninformative about the speaker's stance towards the prejacent.

This leads us to formulate the following:

Homogeneity constraint on $\operatorname{Ideal}_{\mathcal{S}}$.

$\mathcal{O}$ requires that Ideal $_{\mathcal{S}}$ be homogeneous insofar as the prejacent of the modal is concerned.

So, $\mathcal{O}$ requires that, by the time it is computed, all Ideal $_{\mathcal{S}}$ worlds are $p$ worlds or that all Ideal $_{\mathcal{S}}$ are $\neg p$ worlds. This constraint is not merely a stipulation. As just said, if the $\operatorname{Ideal}_{\mathcal{S}}$ set contains both $p$ and $\neg p$ worlds, this would reveal partial commitment towards both the prejacent and its negation. This situation of triviality is to be avoided, and, as the reader can foresee (and shown further in Section 6), it also proves instrumental when we consider the effect of negation.

It is important to note that when $\mathcal{S}$ is non-empty, the bias will be necessarily positive, and the reader can already anticipate, that, in virtue of using $\mathcal{O}$, the necessity modal will not be able to express negative bias. We return to this in detail in Section 6.2. Moreover, as we explain at length in Section 5, by default, existential modals have a non-empty $\mathcal{S}$ and an empty $\mathcal{O}$. By parametrizing existential modals to $\mathcal{O}$, we leave the possibility open that there may be existential modal lexicalizations with non-empty $\mathcal{O}$. NPI-universals, on the other hand, are universals with an empty $\mathcal{O}$, we will suggest, and this allows them to stay in the scope of negation.

In sum, we proposed that the epistemic modal structure involves three ingredients: (i) a nonveridical modal base $\mathrm{M}(i)$, (ii) a secondary modal base $\mathcal{S}$ that partitions $\mathrm{M}(i)$ into $\operatorname{Ideal}_{\mathcal{S}}$ and a $\neg$ Ideal $_{\mathcal{S}}$ subsets, relying on stereotypical assumptions, (iii) a meta-evaluation $\mathcal{O}$ triggered by stereotypicality that ranks the Ideal $_{\mathcal{S}}$ worlds as better possibilities than $\neg$ Ideal $_{\mathcal{S}}$ worlds in $\mathrm{M}(i)$. The preference for higher ranking of Ideal $_{\mathcal{S}}$ is lexically specified, and MUST and MIGHT differ in their lexical preferences (both use $\mathcal{S}$, but higher ranking of Ideal $_{\mathcal{S}}$ is only a feature of MUST). Next, we argue that the adverbs are overt realizations of the meta-evaluation $\mathcal{O}$.

\section{Modal adverbs and verbs: how positive bias is produced}

For universal modals, the role of the adverbs, we propose, is to reflect overtly the positive bias by supplying the meta-evaluation $\mathcal{O}$. The adverbs are thus responsible for the relative ranking of the $\operatorname{Ideal}_{\mathcal{S}}$ as weak necessity with respect to $\neg \mathrm{Ideal}_{\mathcal{S}}$ worlds, or necessity as we shall see. We call the former 'maintaining the default' - since this is the lexical default emerging from the high ranking of stereotypical worlds - and the later 'strengthening the default'. Some languages, as 
we discuss in Section 6.2, also allow 'weakening of the default.'

In Giannakidou and Mari (2013), we noticed the connection between modal adverbs and 'speaker's perspective' and suggested a connection between positive bias and speaker confidence. We asserted that with a necessity epistemic modal "the epistemic agent $i$ has some degree of confidence that the actual world will be a reasonable one"- where reasonable is stereotypical - and that "when a modal adverb is present, the degree of confidence is determined by the adverb. It can be high when the adverb is strong (certainly, definitely, probably), in which case it is harmonic to the force of necessity modal; but it can also be medium $(50 \%)$ or weak (maybe, possibly)." We added that "with no modal adverbs, because of positive bias, the degree of confidence is high (i.e. akin to probably/definitely)." (Giannakidou and Mari 2013:121). Confidence is formulated as a presupposition using a measure function $\mu$ :

Giannakidou and Mari 2013: confidence as a likelihood measure

Presupposition: there is a probability measure function $\mu_{\text {likelihood }}$ determined by $i$ that measures the likelihood, according to $i$ that the actual world is within the set of the best worlds. The default value of $\mu_{\text {likelihood }}$ is probably, above $80 \%$.

Here we find the seeds of the analysis to be developed in the present paper; but our goal is to offer an analysis of adverbs within the framework we developed.

There are three nuances of strength for the adverbs. These are not exhaustive, but they are faithful of the range of possibilities observed in the three languages we are considering.

Effect of the adverbs with universal modals.

a. DEFINITELY (It. assolutamente; Gk. oposdhipote; Eng. definitely): Strengthening the default positive bias.

b. PROBABLY (It. probabilmente; Gk. mallon; Eng. probably): Maintaining the default.

c. MAYBE (It. forse; Gk. isos; Eng. maybe): Weakening the default.

As we discuss in Section 5, existential modality does not use ordering sources (see Kratzer, 1991). MAYBE thus maintains the default lack of bias; adding DEFINITELY or PROBABLY would introduce a bias.

(78) Effect of the adverbs with existential modals.

a. DEFINITELY (It. assolutamente; Gk. oposdhipote; Eng. definitely): Introducing positive bias.

b. PROBABLY (It. probabilmente; Gk. mallon; Eng. probably): Introducing positive bias.

c. MAYBE (It. forse; Gk. isos Eng. maybe): Maintaining the default.

Not all the analytical possibilities are realized in each language; and while default and strengthening with universal modals are allowed in all, Italian and English, unlike Greek, allows weakening with MUST. English and Italian also allow strengthening of possibility modals, two analytical possibilities absent in Greek. Recall the key examples from Section 1:
a. Le luci sono accese. Gianni deve
forse essere a casa.
The lights are switch-on. Gianni must.3SG.PRES maybe be at home.
b. Ta fora one anamena. O Janis prepei \#isos na ine spiti.
The lights are on. The John must maybe be at home.
'The lights are on. John must maybe be at home.' 
c. So there must maybe be some glitch somewhere along the line or something that makes this happen. I am sure is a cache or technical glitchup. ${ }^{21}$

a. \#Bori malon/opsdhipote na efije noris. May probably/definitely subj left.3sG early

b. Può probabilmente essere partito presto.

Can.3SG.PRES probably/certainly be left early.

'\#He may have probably/definitely left early.'

c. In some cases, however, the psychosis might definitely be due to anxieties and conflicts associated with the pregnancy.

We need to develop an analysis that will explain both the combinations observed in all languages (and the general tendency they express for 'harmony'), as well as the less observed (but real) non-harmonic cases.

\subsection{Epistemic MUST and the effect of adverbs}

We start by establishing that for universal modals there is always a silent adverb akin to probably. This adverb provides the baseline positive bias of the modal.

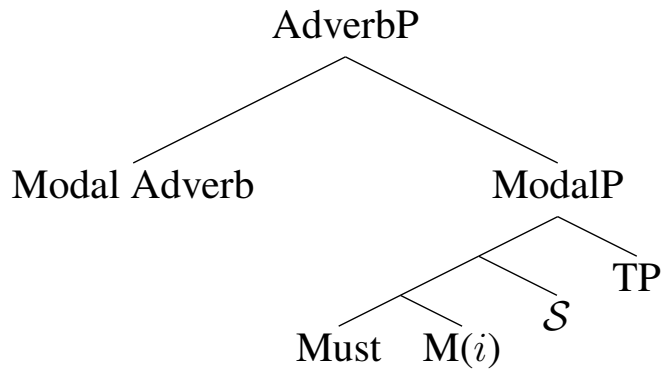

This is the structure of 'modal spread'. The adverb appears adjoined to the ModalP, a position consistent with its syntactic status of epistemic adverb (see Rizzi 1997, Hacquard 2010, and Portner 2009 for more discussion of the high scoping of epistemic adverbs). The adverb can appear following the verb too, and generally the position is interchangeable as it became clear in Section 1. Regardless of position, the adverb is logically interpreted as an adjunct to ModalP, as we propose above. Within ModalP, we find the two arguments $\mathrm{M}(i)$ and $\mathcal{S}$, which are typically covert (unless there is an overt if clause to restrict the modal base). In our structure, the adverbs are expected to occupy the Modal Adverb slot. The following are thus equivalent semantically:
a. John is probably sick.
b. John must probably be sick.
c. John must be sick.

When only the adverb is used, a silent modal is present. If no overt adverb appears, there is a silent adverb, indicated as $\emptyset$. The lexical entry for this silent adverb is as follows. $q$ is the modal proposition MUST(TENSE $(p)$ ). For any $\operatorname{Ideal}_{\mathcal{S}}$,

$$
\begin{aligned}
& \llbracket \emptyset \rrbracket^{\mathcal{O}, \mathrm{M}, i, \mathcal{S}}=\lambda q . \mathrm{Ideal}_{\mathcal{S}} \text { is a weak necessity with respect to } \neg \text { Ideal }_{\mathcal{S}} \text { relative to } \mathrm{M}(i) \text { and } \\
& \mathcal{O} \& q
\end{aligned}
$$

\footnotetext{
${ }^{21}$ Source: https://www.blackhatworld.com/seo/ogads-com-mobile-cpa-cpi-incent-network-mobi $704909 /$ page-26
} 
The default empty $\emptyset$ adverb introduces lexically the weak necessity and the meta-evaluation $\mathcal{O}$. It ranks Ideal $\mathcal{S}$ worlds as higher with respect to $\neg \mathrm{Ideal}_{\mathcal{S}}$.

The higher position is motivated, as we said, by the nature of the epistemic modalityand no special composition rule is need, as one could argue e.g. for evaluative adverbs in a Potts-like framework (Mayol and Castroviejo 2013, Liu 2012). Recall that, as we showed in Section 2, modal adverbs generally disprefer being placed in the left periphery, contrary to purely evaluative adverbs. Some existent theories have defended a view in which the adverbs contribute ancillary commitments (Bonami and Godard, 2008), expressive content (Mayol and Castroviejo 2013, Giannakidou and Mari 2017), or sincerity conditions (Nielsen 2004, Wolf 2013 - see discussion in section 2.1).

In the embedded position the adverbs are interpreted within the local modal structures, we take it therefore that they contribute at the sentence level, as expected since they are epistemic.

Before proceeding with the semantics, let us clarify that our structure differs from Huitink 2012 who argues that adverbs supply the ordering source of the modal. In that analysis, the adverb is a lower argument of the verb. Huitink proposes the following trees (items (55) and (56) in Huitink 2012).

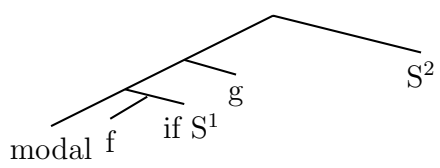

Figure 1: Modal skeleton - Huitink, 2012

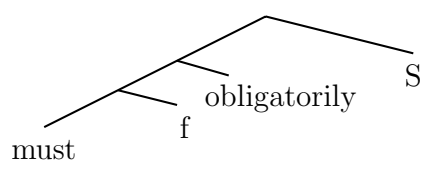

Figure 2: Adverbs provide the ordering source - Huitink, 2012

Huitink's modal "skeleton" renders the adverb a V-adjunction, but in our structure (76) the adverb applies after composition with the modal base and $\mathcal{S}$. Both analyses capture the dispreference for sentence initial position and the embedding data above. Our approach, renders the adverbs flexible with respect to where they will appear: they can be pre-modal or post modal (e.g., must probably, probably must, mallon prepi, prepi mallon, probabilmente deve, deve probabilmente), something expected since they are adverbs thus adjuncts. In the lower analysis, one expects a more rigid syntactic position. On the other hand, in both analyses the adverbs are responsible for the ordering - though in our case the ordering is a meta-evaluation, applying after composition with the other two arguments. ${ }^{22}$

Our analysis, by placing the adverb higher than ModalP, allows for negation to intervene between ModalP and the adverb, and this will be used to explain why MUST cannot scope

\footnotetext{
${ }^{22}$ Furthermore, for Huitink, the adverb provides flavor, whereas for us, by providing bias, it provides force.
} 
inside negation in Section 6. If the adverb were a lower operator and stayed low, we cannot see an explanation of the core positive polarity pattern.

We now have the ingredients to provide the final truth conditions for MUST sentences. Consider first the case without an overt adverb $\left(t_{u}\right.$ still fixed at the time of utterance) but with the default silent one. We augment our earlier truth condition as follows. For any set $\operatorname{Ideal}_{\mathcal{S}}$ and the utterance time $t_{u}$,

(84) $\llbracket \emptyset \operatorname{MUST}(\operatorname{PRES}(p)) \rrbracket^{\mathcal{O}, \mathrm{M}, i, \mathcal{S}}$ is defined only if the modal base $\mathrm{M}(i)$ is nonveridical and it is partitioned into Ideal $_{\mathcal{S}}$ and $\neg \mathrm{Ideal}_{\mathcal{S}}$ worlds. If defined,

$\llbracket \emptyset \operatorname{MUST}(\operatorname{PRES}(p)) \rrbracket^{\mathcal{O}, \mathrm{M}, i, \mathcal{S}}=1$ iff: Ideal $_{\mathcal{S}}$ is a weak necessity with respect to $\neg \mathrm{Ideal}_{\mathcal{S}}$ relative to $\mathbf{M}(i)$ and $\mathcal{O} \& \forall w^{\prime} \in \operatorname{Ideal}_{\mathcal{S}}: p\left(w^{\prime}, t_{u}\right)$

(85) $\llbracket \emptyset \operatorname{MUST}(\operatorname{PAST}(p)) \rrbracket^{\mathcal{O}, \mathrm{M}, i, \mathcal{S}}$ is defined only if the modal base $\mathrm{M}(i)$ is nonveridical and it is partitioned into Ideal $_{\mathcal{S}}$ and $\neg \mathrm{Ideal}_{\mathcal{S}}$ worlds. If defined,

$\llbracket \emptyset \operatorname{MUST}(\operatorname{PAST}(p)) \rrbracket^{\mathcal{O}, \mathrm{M}, i, \mathcal{S}}=1$ iff Ideal $_{\mathcal{S}}$ is a weak necessity with respect to $\neg$ Ideal $_{\mathcal{S}}$ relative to $\mathbf{M}(i)$ and $\mathcal{O} \& \forall w^{\prime} \in \operatorname{Ideal}_{\mathcal{S}}: \exists t^{\prime} \prec t_{u} \wedge p\left(w^{\prime}, t^{\prime}\right)$

The meta-evaluation of Ideal $_{\mathcal{S}}$ worlds is conveyed by the adverb, the default force of which is probably. We now provide the lexical entries for the overt adverbs. $q$ is the ModalP proposition (i.e. MODAL (PAST/PRES $(p)$ ). For any proposition $p$ and any set $\operatorname{Ideal}_{\mathcal{S}}$

$$
\begin{aligned}
& \llbracket \text { Probably/mallon/probabilmente } \rrbracket^{\mathcal{O}, \mathrm{M}, i, \mathcal{S}}= \\
& \lambda q . \mathrm{Ideal}_{\mathcal{S}} \text { is a weak necessity with respect to } \neg \mathrm{Ideal}_{\mathcal{S}} \text { relative to } \mathrm{M}(i) \text { and } \mathcal{O} \& q \\
& \llbracket \text { Definitely/oposdhipote/sicuramente } \rrbracket^{\mathcal{O}, \mathrm{M}, i, \mathcal{S}}= \\
& \lambda q . \text { Ideal }_{\mathcal{S}} \text { is a necessity with respect to } \neg \mathrm{Ideal}_{\mathcal{S}} \text { relative to } \mathrm{M}(i) \text { and } \mathcal{O} \& q \\
& \llbracket \text { Maybe/Forse/Isos } \rrbracket^{\mathcal{O}, \mathrm{M}, i, \mathcal{S}}=\lambda q . \mathcal{O} \text { is empty } \& q
\end{aligned}
$$

The input to the adverb is the modal proposition, and the adverb gives the (lack of) bias as part of the modal meaning. With PROBABLY the bias is maintained: PROBABLY has the same force as the default covert adverb, namely weak necessity. With a stronger adverb (DEFINITELY), we have strengthening of the bias to necessity. This means that the adverb strengthens the default preference of MUST. A possibility adverb adds that $\mathcal{O}$ is empty. This means that there is no bias, no preference for the $\operatorname{Ideal}_{\mathcal{S}}$ set over the $\neg \mathrm{Ideal}_{\mathcal{S}}$ set.

As we have already noted, bias strengthening is the only possible option supported in Greek (79-b). Italian and English allow bias weakening with MUST ((79-c) and (79-a)). We return in Section 6.2 to the reasons according to which bias strengthening is quite a natural operation on the meaning of the modal.

In a syntactic configuration [Modal Adverb [MODAL $p$ ]], then, modal bias is determined by the Modal Adverb. Here are the complete truth conditions after the adverb bias is projected. For any $\operatorname{Ideal}_{\mathcal{S}}$ and the utterance time $t_{u}$,

(90) $\llbracket$ PROBABLY MUST $(\operatorname{PAST}(p)) \rrbracket^{\mathcal{O}, \mathrm{M}, i, \mathcal{S}}$ is defined only if the modal base $\mathrm{M}(i)$ is nonveridical and it is partitioned into Ideal $_{\mathcal{S}}$ and $\neg$ Ideal $_{\mathcal{S}}$ worlds. If defined,

$\llbracket$ PROBABLY MUST $(\operatorname{PAST}(p)) \rrbracket^{\mathcal{O}, \mathrm{M}, i, \mathcal{S}}=1$ iff $\operatorname{Ideal}_{\mathcal{S}}$ is a weak necessity with respect to $\neg \operatorname{Ideal}_{\mathcal{S}}$ relative to $\mathrm{M}(i)$ and $\mathcal{O} \& \forall w^{\prime} \in \operatorname{Ideal}_{\mathcal{S}}: \exists t^{\prime} \prec t_{u} \wedge p\left(w^{\prime}, t^{\prime}\right)$ 
$\llbracket$ DEFINITELY MUST $(\operatorname{PRES}(p)) \rrbracket^{\mathcal{O}, \mathrm{M}, i, \mathcal{S}}$ is defined only if the modal base $\mathrm{M}(i)$ is nonveridical and it is partitioned into $\operatorname{Ideal}_{\mathcal{S}}$ and $\neg \mathrm{Ideal}_{\mathcal{S}}$ worlds. If defined,

$\llbracket$ DEFINITELY MUST $(\operatorname{PRES}(p)) \rrbracket^{\mathcal{O}, \mathrm{M}, i, \mathcal{S}}=1$ iff: $\operatorname{Ideal}_{\mathcal{S}}$ is a necessity with respect to $\neg \mathrm{Ideal}_{\mathcal{S}}$ relative to $\mathrm{M}(i)$ and $\mathcal{O} \& \forall w^{\prime} \in \operatorname{Ideal}_{\mathcal{S}}: p\left(w^{\prime}, t_{u}\right)$

$\llbracket$ DEFINITELY MUST $(\operatorname{PAST}(p)) \rrbracket^{\mathcal{O}, \mathrm{M}, i, \mathcal{S}}$ is defined only if the modal base $\mathrm{M}(i)$ is nonveridical and it is partitioned into Ideal $_{\mathcal{S}}$ and $\neg$ Ideal $_{\mathcal{S}}$ worlds. If defined,

$\llbracket$ DEFINITELY MUST $(\operatorname{PAST}(p)) \rrbracket^{\mathcal{O}, \mathrm{M}, i, \mathcal{S}}=1 \mathrm{iff}^{\mathrm{Ideal}_{\mathcal{S}}}$ is a necessity with respect to $\neg \operatorname{Ideal}_{\mathcal{S}}$ relative to $\mathrm{M}(i)$ and $\mathcal{O} \& \forall w^{\prime} \in \operatorname{Ideal}_{\mathcal{S}}: \exists t^{\prime} \prec t_{u} \wedge p\left(w^{\prime}, t^{\prime}\right)$

Possibility adverbs weaken the bias (see Section 6.2 for this option). Our analysis differs substantially from Moss 2015 (as discussed in Section 2.2), but also from Huitink's (as discussed earlier). It also differs from Grosz (2010), who treats modal adverbs as operators over degrees mapping their prejacents into sets of degrees on a scale of necessity, where adverbs denote the endpoints of scales. Grosz also posits a matching requirement between the force of the modal and the adverb - argued to be a polarity presupposition on the modal degree modifier. In our account, weak necessity bias is hardwired in MUST by the covert adverb.

A binary distinction between universal and existential modality is explored by Anand and Brasoveanu (2010), who claim that the existential modal features a nonveridicality (existence of $\neg p$ worlds) implicature. In their view, universal modality does not give rise to nonveridical inference (it is thus, in our terms, veridical). But as we showed in our discussion of MUST earlier, this cannot be true. Importantly, universal modality is compatible with a range of adverbs (including possibility modals in Italian), a fact not predicted by Anand and Brasoveau.

As we conclude this part of the analysis, we must remind the reader that previous works mostly focus on deontic modality, for which the bias may be stronger (necessity, instead of weak necessity). If that is the case, then we expect less variation with deontic modals, it is therefore less surprising that previous theories cannot predict the more flexible patterns with epistemic modality identified here. Importantly, no rules of concord or feature checking were needed in our discussion, and none of the previous accounts establishes a correlation, as we do, between the modal and the adverb, and the PPI-hood of both. The similar PPI behavior of both modal verbs and adverbs is merely accidental in all accounts we have encountered, and the two phenomena of modal spread and positive polarity are never connected.

\section{Possibility modality}

In agreement with the common analysis of epistemic possibility (Kratzer, 1991), we take it that epistemic possibility modals are existential quantifiers and that they lack ordering sources. ${ }^{23}$ The absence of ordering sources with epistemic possibility modals renders $p$ and $\neg p$ equal possibilities revealing that the assessor is in a state of hesitation and true uncertainty. Following our earlier work (Giannakidou 2013, Giannakidou and Mari 2016b,2018), we call this nonveridical equilibrium. We defined nonveridical equilibrium as the absence of bias, which means, in our current terms, the following.

Nonveridical equilibrium

A partitioned space $\mathrm{M}(i)$ is in nonveridical equilibrium if the ordering $\mathcal{O}$ is empty.

\footnotetext{
${ }^{23}$ Deontic possibility modals are claimed to use a circumstantial modal base and a deontic ordering source (Portner, 2009).
} 
Nonveridical equilibrium implies that $\operatorname{Ideal}_{\mathcal{S}}$ and $\neg \mathrm{Ideal}_{\mathcal{S}}$ are not compared to one another; $p$ and $\neg p$ are equal possibilities, none is privileged over the other. (In addition to possibility modals, information questions are also in nonveridical equilibrium, see Giannakidou 2013). We take equilibrium to be the default for epistemic possibility - though this may be subject to variation (see a brief discussion in Lassiter 2016 and our discussion in Section 6.2).

We assume, as before, that a silent adverb hosts the default preference for equilibrium of bori/potere/might:

(94) $\llbracket \emptyset \operatorname{MIGHT}(\operatorname{PRES}(p)) \rrbracket^{\mathcal{O}, \mathrm{M}, i, \mathcal{S}}$ is defined only if $\mathrm{M}(i)$ is nonveridical and partitioned into Ideal $_{\mathcal{S}}$ and $\neg$ Ideal $_{\mathcal{S}}$ worlds. If defined,

$\llbracket \emptyset \operatorname{MIGHT}(\operatorname{PRES}(p)) \rrbracket^{\mathcal{O}, \mathbf{M}, i, \mathcal{S}}=1$ iff $\mathcal{O}$ is empty $\& \exists w^{\prime} \in \mathbf{M}(i) p\left(w^{\prime}, t_{u}\right)$

(95) $\llbracket \emptyset$ MIGHT (PAST $(p)) \rrbracket^{\mathcal{O}, \mathrm{M}, i, \mathcal{S}}$ is defined only if $\mathrm{M}(i)$ is nonveridical and is partitioned into Ideal $_{\mathcal{S}}$ and $\neg$ Ideal $_{\mathcal{S}}$ worlds. If defined,

$\llbracket \emptyset \operatorname{MIGHT}(\operatorname{PAST}(p)) \rrbracket^{\mathcal{O}, \mathrm{M}, i, \mathcal{S}}=1$ iff $\mathcal{O}$ is empty $\& \exists w^{\prime} \in \mathbf{M}(i) \exists t^{\prime} \prec t_{u} \wedge p\left(w^{\prime}, t^{\prime}\right)$

The covert adverb adds the presupposition that $\mathcal{O}$ is empty. Note also that the existential quantifier operates on the entire modal base $\mathrm{M}(i)$ and not on one of the subsets created by $\mathcal{S}$ (and Ideal $\mathcal{S}_{\mathcal{S}}$ in particular). This amounts to stating that the quantifier is blind to stereotypicality conditions in spite of the fact that these are always operational in the cognitive system of the anchors (note also that there might be $p$ worlds which are not in the set $\operatorname{Ideal}_{\mathcal{S}}$ ). Stereotypicality conditions, however, as we explain in Section 6.2, can also trigger a non-empty $\mathcal{O}$ for MIGHT in some languages.

Recall the entries of the adverbs in (86)-(88), which we repeat below. For any proposition $p$ and set Ideal $_{\mathcal{S}}$,

$$
\begin{aligned}
& \llbracket \text { Probably/mallon/probabilmente } \rrbracket^{\mathcal{O}, \mathrm{M}, i, \mathcal{S}}= \\
& \lambda q . \mathrm{Ideal}_{\mathcal{S}} \text { is a weak necessity with respect to } \neg \mathrm{Ideal}_{\mathcal{S}} \text { relative to } \mathrm{M}(i) \text { and } \mathcal{O} \& q \\
& \llbracket \text { Definitely/oposdhipote/sicuramente } \rrbracket^{\mathcal{O}, \mathrm{M}, i, \mathcal{S}}= \\
& \lambda q . \text { Ideal }_{\mathcal{S}} \text { is a necessity with respect to } \neg \operatorname{Ideal}_{\mathcal{S}} \text { relative to } \mathrm{M}(i) \text { and } \mathcal{O} \& q \\
& \llbracket \text { Maybe/Forse/Isos } \rrbracket^{\mathcal{O}, \mathrm{M}, i, \mathcal{S}}=\lambda q . \mathcal{O} \text { is empty } \& q
\end{aligned}
$$

Just as the presence of stereotypicality conditions with universal modals triggers positive bias (i.e. higher ranking of the $\operatorname{Ideal}_{\mathcal{S}}$ over non-Ideal ${ }_{\mathcal{S}}$ ), the absence of stereotypicality conditions with existential modal does not enhance any ranking.

In virtue of this, the most straightforward combination which we find in all languages is MAYBE + MIGHT. When we add MAYBE we obtain (100)-(99). The combination maintains the default, which now is nonveridical equilibrium. With possibility modals, MAYBE has no effect on the equilibrium, since it does not provide ranking. For any proposition $p$ and the utterance time $t_{u}$,

$\llbracket$ MAYBE MIGHT $(\operatorname{PRES}(p)) \rrbracket^{\mathcal{O}, \mathrm{M}, i, \mathcal{S}}$ is defined only if $\mathrm{M}(i)$ is nonveridical and is partitioned into Ideal $_{\mathcal{S}}$ and $\neg$ Ideal $_{\mathcal{S}}$ worlds. If defined, $\llbracket \operatorname{MAYBE} \operatorname{MIGHT}(\operatorname{PRES}(p)) \rrbracket^{\mathcal{O}, \mathbf{M}, i, \mathcal{S}}=1$ iff $\mathcal{O}$ is empty $\& \exists w^{\prime} \in \mathbf{M}(i) p\left(w^{\prime}, t_{u}\right)$

$\llbracket$ MAYBE MIGHT $(\operatorname{PAST}(p)) \rrbracket^{\mathcal{O}, \mathrm{M}, i, \mathcal{S}}$ is defined only if $\mathrm{M}(i)$ is nonveridical and is partitioned into Ideal $_{\mathcal{S}}$ and $\neg$ Ideal $_{\mathcal{S}}$ worlds. If defined,

$\llbracket \operatorname{MAYBE} \operatorname{MiGHT}(\operatorname{PAST}(p)) \rrbracket^{\mathcal{O}, \mathrm{M}, i, \mathcal{S}}=1$ iff $\mathcal{O}$ is empty \& $\exists w^{\prime} \in \mathbf{M}(i) \exists t^{\prime} \prec t_{u} \wedge$ $p\left(w^{\prime}, t^{\prime}\right)$

As we note in Section 6.2, languages may vary and the nonveridical equilibrium can be 
strengthened into bias if $\mathcal{O}$ is non-empty.

Possibility modals are not forced to scope above negation and, as we shall see in Section 6, the situation of equilibrium is compatible with both scopes. Empirically, possibility modals tend to scope below negation crosslinguistically. In John cannot be at home, the possibility is denied that John is at home. The reason for this preference, we want to suggest, seems to be that low scope with negation appears to be the general case with all kinds of existentials: Ariadne didn't see any student/ a student/ one student all scope below negation. If this is a general tendency of existential quantifiers, possibility modals simply follow this systemic pattern. (There do appear to be PPI existentials like some-Ariadne didn't see SOME student- but note that this use is marked; Giannakidou 2011)). It is an open question whether PPI possibility modals can be found in languages. Our analysis predicts, in any case, both scopes.

\section{Why are MUST and necessity modals PPIs?}

\subsection{Negation, MUST, and the adverb}

We are now ready to explain why epistemic MUST scopes above negation. Recall the truth conditions for MUST (we only consider here the PRES option for simplicity).

(101) $\llbracket$ PROBABLY MUST (PRES $(p)) \rrbracket^{\mathcal{O}, \mathrm{M}, i, \mathcal{S}}$ is defined only if the modal base $\mathrm{M}(i)$ is nonveridical and it is partitioned into Ideal $_{\mathcal{S}}$ and $\neg$ Ideal $_{\mathcal{S}}$ worlds. If defined,

$\llbracket$ PROBABLY MUST $(\operatorname{PRES}(p)) \rrbracket^{\mathcal{O}, \mathrm{M}, i, \mathcal{S}}=1$ iff: Ideal $_{\mathcal{S}}$ is a weak necessity with respect to $\neg \mathrm{Ideal}_{\mathcal{S}}$ relative to $\mathrm{M}(i)$ and $\mathcal{O} \& \forall w^{\prime} \in \operatorname{Ideal}_{\mathcal{S}}: p\left(w^{\prime}, t_{u}\right)$

MUST presupposes a nonveridical modal base and a non-empty $\mathcal{O}$; it universally quantifies over the Ideal $_{\mathcal{S}}$ worlds. When we add negation, we have the truth conditions in (103):

a. Malon dhen prepi na ine giatros

Probably not must be.PRES a doctor.

b. Probabilmente non deve essere un dottore.

Probably not must be a doctor.

'He must not be a doctor.'

$\llbracket$ PROBABLY NOT MUST $(\operatorname{PRES}(p)) \rrbracket^{\mathcal{O}, \mathrm{M}, i, \mathcal{S}}$ is defined only if the modal base $\mathrm{M}(i)$ is nonveridical and it is partitioned into $\operatorname{Ideal}_{\mathcal{S}}$ and $\neg \mathrm{Ideal}_{\mathcal{S}}$ worlds. If defined,

$\llbracket$ PROBABLY NOT MUST $(\operatorname{PRES}(p)) \rrbracket^{\mathcal{O}, \mathrm{M}, i, \mathcal{S}}=1$ iff: Ideal $_{\mathcal{S}}$ is a weak necessity with respect to $\neg \operatorname{Ideal}_{\mathcal{S}}$ relative to $\mathbf{M}(i)$ and $\mathcal{O} \& \forall w^{\prime} \in \operatorname{Ideal}_{\mathcal{S}}: \neg p\left(w^{\prime}, t_{u}\right)$

When combined with negation, the resulting interpretation is as in (103): all the ideal worlds are $\neg p$ worlds. The adverb ranking, which remains intact along with the nonveridicality presupposition, will again rank as higher the $\operatorname{Ideal}_{\mathcal{S}}$ worlds than the $\neg \mathrm{Ideal}_{\mathcal{S}}$ ones. In this case, the Ideal $_{\mathcal{S}}$ ones are worlds where $\neg p$ is true. This interpretation reveals the PPI-hood of MUST. Why can't negation be interpreted between the adverb and the verb, as in the surface structure?

Negation in Greek and Italian is preverbal, and appears directly preceding the modal verb (Zanuttini 1992, Giannakidou 1998): 


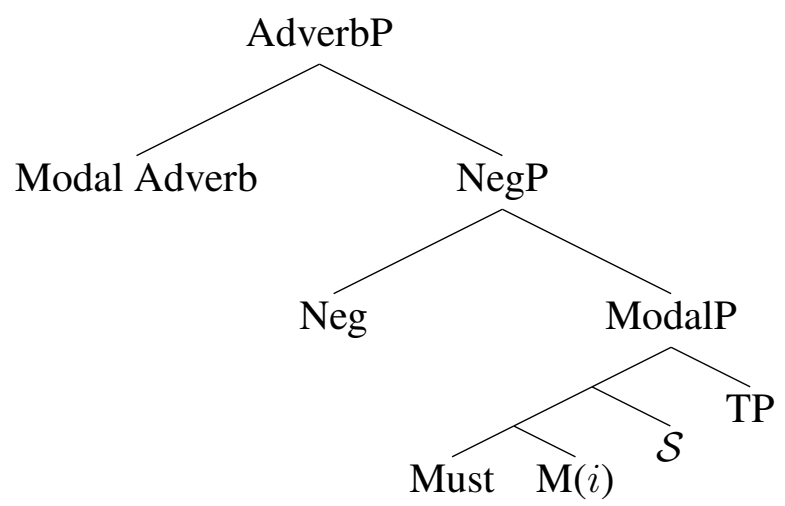

The adverb appears above negation and can never intervene between negation and the modal:
a. *Dhen malon prepi.
Not probably must.
b. *Non probabilmente deve.
Not probably must.

We observe the same distributions for the existential.
a. Isos dhen bori.
Maybe not can.
b. Forse non può.
Maybe not can.
a. *Dhen isos bori.
Not maybe can.
b. *Non forse può.
Not maybe can.

Hence the adverb must be above the negation syntactically. Crucially, the adverb can never appear lower than negation, even in English, as we noted in Section 1, repeated here:

(108) \#Ariadne must not probably/definitely be at home.

Only a metalinguistic negation reading is acceptable here, which is irrelevant. In other words, scoping of modal adverbs under negation seems to be generally prohibited in languages. In English, must precedes negation (must not) anyway, and the constraint on the adverb not scoping low also holds, (108).

Now, what would it mean for the structure to be interpreted with negation scoping between the adverb and the modal verb as given in (104)? The corresponding truth conditions would be as in (109):

$\llbracket$ PROBABLY NOT MUST (PRES $(p)) \rrbracket^{\mathcal{O}, \mathrm{M}, i, \mathcal{S}}$ is defined only if the modal base $\mathrm{M}(i)$ is nonveridical and it is partitioned into Ideal $_{\mathcal{S}}$ and $\neg \mathrm{Ideal}_{\mathcal{S}}$ worlds. If defined, $\llbracket$ PROBABLY NOT MUST $(\operatorname{PRES}(p)) \rrbracket^{\mathcal{O}, \mathrm{M}, i, \mathcal{S}}=1$ iff: Ideal $_{\mathcal{S}}$ is a weak necessity with respect to $\neg \mathrm{Ideal}_{\mathcal{S}}$ relative to $\mathbf{M}(i)$ and $\mathcal{O} \& \neg \forall w^{\prime} \in \mathrm{Ideal}_{\mathcal{S}}: p\left(w^{\prime}, t_{u}\right)$

The default adverb retains the content that $\operatorname{Ideal}_{\mathcal{S}}$ is a weak necessity relative to $\mathcal{O}$, but $\mathrm{Ideal}_{\mathcal{S}}$ now is targeted by negation and can be non-homogenous. This means that the homogeneity constraint on Ideal $_{\mathcal{S}}$ is not satisfied (recall the constraint in (75)), and this leads to infelicity. To 
repair the infelicity the negation is interpreted below the modal.

Recall our discussion in Section 3.2.2. We said there that the ranking of the Ideal $_{\mathcal{S}}$ worlds with respect to $\neg \operatorname{Ideal}_{\mathcal{S}}, \mathcal{O}$ is intended to capture $i$ 's confidence in the truthfulness of the prejacent. In order to successfully establish this comparison between $\operatorname{Ideal}_{\mathcal{S}}$ and $\neg \mathrm{Ideal}_{\mathcal{S}}$ worlds and express confidence towards the prejacent, $\operatorname{Ideal}_{\mathcal{S}}$ needs to be homogeneous insofar as the prejacent is concerned. $\mathcal{O}$ cannot produce a well-formed ranking if the $\mathrm{Ideal}_{\mathcal{S}}$ set is itself partitioned, as this would reveal confidence in both $p$ and $\neg p$ worlds and the sentence would become uninformative about the speaker's stance towards $p$.

In other words, the positive polarity property of MUST is derived as a result of its semantics that includes the ranking of Ideal $_{\mathcal{S}}$ worlds as better possibilities than $\neg$ Ideal $_{\mathcal{S}}$ worlds, which itself forces homogeneity on the $\operatorname{Ideal}_{\mathcal{S}}$ set. As we saw at the beginning of this section, with negation scoping low, the modal delivers a homogeneous $\operatorname{Ideal}_{\mathcal{S}}$ set, and $\mathcal{O}$ can now apply successfully, with the bias being towards $\neg p$ worlds.

As regards NPI-universals like need, hoeven, xreiazete (which are typically deontic), we propose that the higher (adverb) content is neutralized. Making this precise in the context of our theory so far is to say that NPI necessity modals have an empty $\mathcal{O}$. That would be a lexical feature of them that, in contrast to epistemic PPI universals, renders them compatible with higher negation. The two necessity modals would thus differ by lexical properties.

With Ernst (2009) and Homer (2015), we are assuming a clash between homogeneity and negation. However, there are major differences that result in a larger empirical coverage of our account, and an explanation of both phenomena of PPI-hood and modal spread. First, our homogeneity is not at the level of the modal base. Specifically we are appealing to a conflict between the default adverbial contribution $\left(\mathcal{O}\right.$, positive bias towards $\left.\operatorname{Ideal}_{\mathcal{S}}\right)$ and the non-homogeneity produced by negation. Homogeneity is for us a constraint imposed by $\mathcal{O}$ on the internal constitution of the $\operatorname{Ideal}_{\mathcal{S}}$ set.

Second, Ernst and Homer assume subjectivity and 'opinionatedness' for MUST with a homogenous modal base - which, we argued, is not justified. We took pains to show that MUST $p$ is incompatible with knowledge or belief of $p$. As we argued, modals are epistemic weakeners, and by using them the speaker is not opinionated about, or fully committed to the prejacent.There is uncertainty in MUST because of the nonveridicality of the modal base which allows both $p$ and $\neg p$ worlds.

Finally, while homogeneity is a presupposition with which negation clashes, the contribution of the modal itself, via the ranking, is part of the assertion. This ensures that our account is, unlike previous ones, flexible enough to capture the PPI-hood of the modal (as just shown) and its compatibility with a variety of adverbs of different strengths (that it is to say, modal spread), as we now show. Explaining the two phenomena would not be possible if the whole contribution of the meaning introduced by the adverb were located at the presuppositional level.

\subsection{Cross-linguistic variation: how much can $\mathcal{O}$ be negotiated?}

We are now ready to explain cross-linguistic variation. Recall once again that Italian and English are more tolerant than Greek and allow the combinations MUST + MAYBE.
a. Le luci sono accese. Gianni deve forse essere a casa. The lights are switch-on. Gianni must.3SG.PRES maybe be at home.
b. Ta fota one anamena. $\mathrm{O}$ Janis prepei/\#isos na ine spiti. The lights are on. \#The John must maybe be at home. 'The lights are on. \#John must maybe be at home.' 
c. So there must maybe be some glitch somewhere along the line or something that makes this happen. I am sure is a cache or technical glitchup ${ }^{24}$

We proposed an analysis of MUST and the adverb triggering positive bias by using stereotypicality conditions, and ranking the stereotypical Ideal $_{\mathcal{S}}$ worlds as higher. Given that ordering sources are easily negotiable (Rubinstein 2014, Portner and Rubinstein, 2016), the question is: how much? We expect some variation cross-linguistically, and here we make predictions that can be confirmed or challenged by further research on other languages.

Recall that bias can be strengthened, as when DEFINITELY combines with MUST. Bias strengthening is a possibility that exists across all languages under discussion (Greek, Italian and English). Strengthening does not contravene the default positive bias of MUST, and appears to be a natural tendency.

Given the preference for positive bias of MUST, many languages, including Greek, ban the combination MUST + MAYBE, as MAYBE does not introduce ranking and is an indicator of equilibrium. However, occasionally, the observed preference is negotiated, and MUST can combine with MAYBE. $\mathcal{O}$ is now empty:

$\llbracket$ MAYBE MUST $(\operatorname{PAST}(p)) \rrbracket^{\mathcal{O}, \mathrm{M}, i, \mathcal{S}}$ is defined only if $\mathrm{M}(i)$ is nonveridical and is partitioned into Ideal $_{\mathcal{S}}$ and $\neg$ Ideal $_{\mathcal{S}}$ worlds. If defined,

$\llbracket \operatorname{MAYBE} \operatorname{MUST}(\operatorname{PAST}(p)) \rrbracket^{\mathcal{O}, \mathrm{M}, i, \mathcal{S}}=1$ iff $\mathcal{O}$ is empty $\& \forall w^{\prime} \in \operatorname{Ideal}_{\mathcal{S}} \exists t^{\prime} \prec t_{u} \wedge$ $p\left(w^{\prime}, t^{\prime}\right)$

This is an analytical option that some languages, like Italian and English, realize. This analytical option can be realized insofar as $\mathcal{O}$ is a parameter, and it can either be empty or not. However, an empty ordering source combining with a modal that prefers a non-empty one overrules the lexical tendency of MUST, and is therefore a less common operation.

With possibility modals, $\mathcal{O}$ is empty, and we expect them to combine easily with adverbs that are similar. For this reason, Greek, English and Italian possibility modals combine unproblematically with MAYBE. However, as we mentioned earlier, the combination MAYBE + PROBABLY and even DEFINITELY, is not rare across languages.

a. \#Bori malon/opsdhipote na efije noris. May probably/definitely subj left.3SG early

b. Può probabilmente essere partito presto. Can.3SG.PRES probably/certainly be left early. '\#He may have probably/definitely left early.'

c. In some cases, however, the psychosis might definitely be due to anxieties and conflicts associated with the pregnancy.

In Italian and English, we obtain what follows. Given the set Ideal $_{\mathcal{S}}$ and the utterance time $t_{u}$,

【PROBABLY MIGHT $(\operatorname{PAST}(p)) \rrbracket^{\mathcal{O}, \mathrm{M}, i, \mathcal{S}}$ is defined only if $\mathrm{M}(i)$ is nonveridical and is partitioned into Ideal $_{\mathcal{S}}$ and $\neg \operatorname{Ideal}_{\mathcal{S}}$ worlds. If defined,

$\llbracket \operatorname{PROBABLY}$ MIGHT $(\operatorname{PAST}(p)) \rrbracket^{\mathcal{O}, \mathrm{M}, i, \mathcal{S}}=1$ iff

Ideal $_{\mathcal{S}}$ is a weak necessity with respect to $\neg \operatorname{Ideal}_{\mathcal{S}}$ relative to $\mathrm{M}(i)$ and $\mathcal{O} \& \exists w^{\prime} \in$ $\mathbf{M}(i) \exists t^{\prime} \prec t_{u} \wedge p\left(w^{\prime}, t^{\prime}\right)$

\footnotetext{
${ }^{24}$ Source: https: //www.blackhatworld.com/seo/ogads-com-mobile-cpa-cpi-incent-network-mobi $704909 /$ page-26. We thank Paul Portner for pointing this to us.
} 
Again, this is an analytical possibility that some languages realize insofar as $\mathcal{O}$ is also a parameter of the existential modals that can, or cannot, be empty. Note that the resulting interpretation is not parallel to the bare MUST as the domain of quantification of the existential remains $\mathrm{M}(i)$ and the modal maintains its existential meaning. ${ }^{25}$ However, while there is no contradiction in (113), the two conjuncts in the truth conditions create a cacophony that most of the languages avoid. Greek does exactly that.

In sum, because combining a non-ordering possibility modal with an adverb that provides a non-empty ordering source goes against the natural inclination, the occurrence is more rare. But it is not excluded. We therefore conclude that, while keeping $\mathcal{O}$ empty with existential modals and non-empty with universal modals is the most reasonable option for both the modals and the meta-evaluation in line with an important portion of the data, it is not a logical necessity to have only harmonic combinations.

Finally, if $\mathcal{O}$ can be negotiated, why don't we have negative bias? Our answer is the following: there is no parameter available for non-stereotypicality conditions, hence lower ranking of the domain of quantification of the modals is impossible. Our theory therefore predicts that, while it is possible to manipulate (upgrade or downgrade, as we saw) the default preferences of all modals - and to discard the preference of universal modals for positive bias and of the existential modal for lack of bias-, it is not possible to introduce a negative bias. The absence or, at best, extreme rarity of negative epistemic adverbs (*un-definitely, *un-maybe) supports this line of reasoning; recall that even the rare negative adverbs cannot be used in modal spread. One may find, for instance, improbably and unlikely, but neither one is used in modal spread:

\section{\#Ariadne must/may unlikely/improbably be a doctor.}

The reluctance of negative epistemic modal adverbs to participate in modal spread is evidence that the modals cannot express negative bias. Given what we said so far, none of the parameters of the existential and universal modals allow to encode preference for the set in which the prejacent is not true. Recall that the ordering can be triggered by stereotypicality and that stereotypicality can cause the stereotypical set to be ranked higher and not lower. In other words, epistemic necessity and possibility are both lexically 'positive' in virtue of the fact that stereotypicality conditions trigger bias towards the set in which the prejacent is true. This seems to be a lexical property of all modals in language once sterotypicality is introduced. Crucially, there is no parameter available for non-stereotypicality conditions, therefore lower ranking of the domain of quantification of the modals is impossible.

\section{Conclusions}

In this paper, we addressed the common observation that epistemic modal verbs and adverbs are PPIs. We decided to study their behavior by examining modal spread- a phenomenon which, like all spread or concord phenomena in language, can appear to be redundant or even anomalous, since it involves two apparent modal operators being interpreted as a single modality. We defended the following positions:

1. Epistemic necessity modals are nonveridical, which means that they are incompatible with knowledge of $p$. Their nonveridical modal base includes a set of Ideal $_{\mathcal{S}}$ and a set of non-Ideal $_{\mathcal{S}}$ worlds. Ideal $\mathcal{S}_{\mathcal{S}}$ is ranked by a meta-evaluation $\mathcal{O}$ as a better possibility than $\neg \mathrm{Ideal}_{\mathcal{S}}$ set, thus rendering epistemic universal modals inherently positively biased.

\footnotetext{
${ }^{25}$ Unlike in St'aátimcets Matthewson et al. 2007 Greek, Italian and English distinguish modals according to force and the dimension that is manipulated is not force but ordering (i.e. bias).
} 
2. The adverb is the realization of $\mathcal{O}$. The positive bias is towards the $\operatorname{Ideal}_{\mathcal{S}}$ set, which contains only $p$ or only $\neg p$ worlds (when the sentence is negated). Given the bias towards $\mathrm{Ideal}_{\mathcal{S}}$, the MUST sentence conveys that the actual world is more likely to be one in which the prejacent is true.

3. Modal bases are either in nonveridical equilibrium (with existential, possibility modals), which means that $\mathcal{O}$ is empty, or there is positive bias, as is the case with MUST.

4. The tendency is for the adverbs to observe the inherent positive bias of the modal - given, we argued, by a null adverb -, or to strengthen it. However, whether $\mathcal{O}$ is empty or nonempty maybe negotiable in some languages, and Italian and English allow the option of empty $\mathcal{O}$ with universal modal, and non-empty $\mathcal{O}$ with an existential. These options target the default specifications of the modals, and are therefore less common.

5. Although bias is negotiable, there is never negative bias because stereotypicality can only trigger an ordering source $\mathcal{O}$ that ranks the stereotypical set higher, and there is no modal parameter available for non-stereotypicality conditions. This explains why MUST cannot combine with negative epistemic adverbs (which are indeed quite rare).

6. Universal epistemic modal verbs are PPIs because of the semantic ingredients they contain. If negation is interpreted between the adverb and the verb (i.e as in its surface position), it creates non-homogeneity in the $\operatorname{Ideal}_{\mathcal{S}}$ set, which would contain both $p$ worlds and $\neg p$ worlds. As a result, application of ranking will be infelicitous (since the ranking would target $p$ and $\neg p$ worlds at the same time, with the sentence becoming uninformative about the speaker's stance towards the prejacent). NPI-MUST, on the other hand, contains an empty $\mathcal{O}$, therefore no ranking, and it can stay in the scope of negation.

In our analysis, modal spread emerges not as a redundancy, but as explicitly realizing the additional layer of $\mathcal{O}$. As we said, $\mathcal{O}$ is a parameter, and we may find possibility modals with nonempty $\mathcal{O}$, or necessity modals with an empty one (as we just claimed the NPI MUST is). Our analysis makes the adverbs an integral component of modality; modal spread is the canonical structure of modality even if one piece (the adverb or the verb) is missing. We approached the puzzles differently from feature checking accounts (e.g. Zeijlstra to appear), and our theory is, we believe, better equipped to capture the nuanced data observed in this paper. Note, finally, that we relied on the standard premises of linguistic theories of modality (Kratzer 1991, Giannakidou 1998, 1999, Portner 2009, Mari, 2015, Portner and Rubinstein 2016, Giannakidou and Mari 2013, 2016b, 2017, 2018), and we did not have to make any extraordinary assumptions.

\section{Acknowledgements}

No work is done is isolation, and we want to thank the many colleagues that became familiar with our work and offered us comments when we presented material related to this paper, as early as the 'Futur dans les langues Romanes' workshop held in in Neuchâtel in 2012, the Amsterdam Colloquium in 2013, and the Linguistics and Philosophy seminar in Chicago in 2014. The specific shape of the material discussed in this paper owes a lot to the insights and advice we received from our editor Paul Portner, who went beyond the call of duty to encourage us to develop our arguments to their fullest. We are thankful for his help. Many thanks also to Jason Merchant and Hedde Zeijlstra for their suggestions on the more syntactic aspects of the paper, to Mingya Liu, Claire Beyssade and Lavi Wolf for their comments on epistemic commitment and to the anonymous reviewers of Linguistics and Philosophy for their careful reading of the paper, and for offering generously their suggestions and insights. 


\section{References}

Abusch, D. 2004. On the temporal composition of infinitives. In J. Guéron and J. Lecarme (eds.). The Syntax of Time, MIT Press, pp. 1-34.

Anand, P. and A. Brasoveanu (2010). Modal concord as modal modification. In Proceedings of Sinn und Bedeutung 14, pp. 19-36.

Anand, P. and Hacquard, V. 2013. Epistemics and Attitudes. Semantics and Pragmatics 6: $1-59$.

Asher, N. and Morreau, M. 1995. What some generic sentences mean. In G. Carlson and F.J. Pelletier (eds.). The Generic Book. Chicago: CUP.

Bertinetto, P.M. 1979. Alcune ipotesi sul nostro futuro (con alcune osservazioni su potere e dovere), Rivista di grammatica generativa 4: 77-138.

Beaver, D. and Frazee, J. 2016. Semantics. In The Handbook of Computational Linguistics. Online Publication DOI:10.1093/oxfordhb/9780199573691.013.29

Bonami, O. and Godard, G. 2008. Lexical semantics and pragmatics of evaluative adverbs. In L. McNally and C. Kennedy (eds.). Adverbs and adjectives: Syntax, semantics and discourse. Oxford: Oxford University Press, pp. 274-304.

Condoravdi, C. 2002. Temporal interpretation of modals: modals for the present and for the past. In The Construction of Meaning, eds D. Beaver, Luis D. Cassillas Maritinez, Brady Z. Clark, S. Kaufmann.

Cui, Y. 2015. Modals in the scope of attitudes: a corpus study of attitude-modal combinations in Mandarin Chinese. PhD Georgetown University.

Dowty, D. 1979. Word Meaning and Montague Grammar. Dordrech: Kluwer.

Ernst, T. 2009. Speaker oriented adverbs. Natural Language and Linguistic Theory 27, 497544.

Farkas, Donka. 1985. Intensional Descriptions and the Romance Subjunctive. New York: Garland.

von Fintel, K. and Gillies, A. 2010. Must...stay... strong ! Nat. Language Semantics 18: 351-383.

von Fintel, K. and Iatridou, S. (2008). How to say ought in foreign: The composition of weak necessity modals. In J. Guéron and J. Lacarme (eds.) Time and Modality Springer, pp. 115141.

von Fintel, K. and Iatridou, S. 2008. How to Say Ought in Foreign: The Composition of Weak Necessity Modals. In J Guéron and J. Lacarme (eds.). Time and Modality. Dordrecht: Springer, pp. 115-141.

Giannakidou, A. 1994. The Semantic licensing of NPIs and the Modern Greek subjunctive. In Ale de Boer, Helen de Hoop, Henriette de Swart (eds), Language and Cognition 4, Yearbook of the Research Group for Theoretical and Experimental Linguistics, University of Groningen: 55-68.

Giannakidou, A. 1997. The Landscape of Polarity Items . PhD thesis, University of Groningen. Amsterdam.

Giannakidou, A. 1998. Polarity Sensitivity as (Non)veridical Dependency. John Benjamins. Amsterdam.

Giannakidou, A. 1999. Affective dependencies. Linguistics and Philosophy 22: 367- 421.

Giannakidou, A. 2009. The dependency of the subjunctive revisited: temporal semantics and polarity. Lingua 120: 1883-1908.

Giannakidou, A. 2011. Positive polarity items and negative polarity items: variation, licensing, and compositionality. In Semantics: An International Handbook of Natural Language Meaning (Second edition; ed. by C. Maienborn, K. von Heusinger, and P. Portner). Berlin: 
Mouton de Gruyter.

Giannakidou, A. 2012. The Greek future as an epistemic modal. In the Proceedings of ICGL 10 .

Giannakidou, A. 2013. Inquisitive assertions and nonveridicality. In The dynamic, inquisitive, and visionary life of $\phi, ? \phi$ and possibly $\phi$, A feestschrift for Jeroen Groenendijk, Martin Stokhof and Frank Veltman, ed. by Maria Aloni, Michael Franke, F. Roelofsen: 115-126.

Giannakidou, A. and Mari, A. 2012a. Italian and Greek futures as epistemic operators. Proceedings of CLS 48, pp. 247-262.

Giannakidou, A. and Mari, A. 2012b. The future of Greek and Italian: An epistemic analysis. Proceedings of Sinn und Bedeutung 17: 255-270. http: / / semanticsarchive.net / Archive/Dk3NGEwY/GiannakidouMari.pdf

Giannakidou, A. and Mari, A. 2013. A two dimensional analysis of the future: modal adverbs and speaker's bias. Proceedings of the Amsterdam Colloquium 2013, pp. 115-122.

Giannakidou, A. and Mari, A. 2016a. Emotive predicates and the subjunctive: a flexible mood OT account based on (non)veridicality. In Proceedings of Sinn und Bedeutung 20, pp. 288305.

Giannakidou A. and Mari, A. 2016b. Epistemic future and epistemic MUST: nonveridicality, evidence, and partial knowledge. In Tense, Mood, and Modality : New Perspectives on Old Questions, ed. by Blaszack, J. et al., University of Chicago Press.

Giannakidou, A. and Mari, A. 2017. La dimension épistemique du futur : le rôle des adverbes. In Baranzini and de Saussure (eds). Le Futur dans les langues Romanes. Peter Lang AG.

Giannakidou, A. and Mari, A. 2018. A unified analysis of the future as epistemic modality: the view from Greek and Italian. Natural Language and Linguistic theory 36: 85Đ129.

Giorgi, A. and Pianesi, F. 1997. Tense and Aspect: Form Semantics to Morphosyntax. Oxford: Oxford University Press.

Grosz, P. 2010. Grading modality: a new approach to modal concord and its relatives. In Proceedings of Sinn und Bedeutung 14, pp. 185-201. http://www. univie.ac.at/ sub14/http: //www. univie.ac.at/sub14/.

Geurts, B. and Huitink, J. 2006. Modal concord. In P. Dekker and H. Zeijlstra (eds.), Concord and the syntax-semantics interface. ESSLLI, Malaga, pp. 15-20.

Gunlogson, C. 2001. True to Form: Rising and Falling Declaratives in English, Ph.D. UCSC.

Hacquard, V. 2006. Aspects of Modality. PhD MIT.

Hacquard, V. 2010. On the Event Relativity of Modal Auxiliaries. Natural Language Semantics 18(1): 79-114.

Hacquard, V. Wellwood, A. 2012. Embedding epistemic modals in English: A corpus-based study. Semantics and Pragmatics, 5(4): 1-29.

Hamblin, C. 1970, Fallacies, London: Methuen.

Harris, J. A. and Potts, C. 2009. Perspective-shifting with appositives and expressives. Linguistics and Philosophy 32(6): 523-552.

Homer, V. 2015. Neg-raising and positive polarity: The view from modals. Semantics \& Pragmatics 8: 1-88.

Halliday, M. A. K. 1970. Functional diversity in language as seen from a consideration of modality and mood in English. Foundations of Language 6: 322-361.

Hintikka, J. 1962. Knowledge and Belief. Cornell: Cornell University Press.

Huitink, J. 2012. Modal concord. A case study in Dutch. Journal of Semantics 29(3): 403-437.

Huitink, J. 2014. Modal concord. Submitted to The Blackwell Companion to Semantics, edited by Lisa Matthewson, Cécile Meier, Hotze Rullman and Thomas Ede Zimmermann.

Iatridou, S. and Zeijlstra, H. 2013. Negation, polarity and deontic modals. Linguistic Inquiry 
44: $529-568$.

Israel, M. 1996. Polarity sensitivity as lexical semantics. Linguistics and Philosophy 19(6): 619-666.

Karttunen, L. 1971. Some observations on factivity. Papers in Linguistics 4:1: 55-69.

Karttunen, L. 1972. Possible and must. Syntax and Semantics: volume 1. J. Kimball. New York, Academic Press: 1-20.

Knobe, J. and Szabo, G.S. 2013. Modals with a taste of the deontic. Semantics and Pragmatics 6: 1-42.

Kratzer, A. 1981. The Notional Category of Modality. In Words, Worlds, and Contexts. New Approaches in Word Semantics, ed. By H. J. Eikmeyer \& H. Rieser, 38? 74. Berlin: de Gruyter.

Kratzer, A. 1991. Modality. In Semantics: An International Handbook of Contemporary Research, ed. By A. von Stechow \& D. Wunderlich, 639-650. Berlin: de Gruyter.

Krifka, M. 2015. Bias in Commitment Space Semantics: Declarative questions, negated questions, and question tags. Proceedings of SALT 25, 328-345.

Landman, F. 1992. The progressive. Natural language semantics, 1(1): 1-32.

Lasersohn, P. 2005. Context dependence, disagreement, and predicates of personal taste. Linguistics and Philosophy 28: 643-686.

Lassiter, D. 2014. The weakness of must: In defense of a Mantra. Proceedings of SALT 24: 597-618.

Lassiter, Daniel. 2016. Must, knowledge, and (in)directness. Natural Language Semantics 24: 117-163.

Lauer, S. 2013. Towards a dynamic pragmatics. PhD Stanford.

Liu, M. 2009. Speaker-Oriented adverbs of the German -weise sort. Proceedings of Sinn ind Bedeutung 2009, 333-346.

Liu, M. 2012. Multidimensional semantics for evaluative adverbs. Brill.

Lyons, J. 1977. Semantics. Cambridge University Press, Cambridge

Mari, A. 2003. Principes d'identification et de catégorisation du sens: le cas de 'avec' ou l'association par les canaux. Paris: L'Harmattan.

Mari, A. 2005. Intensional and epistemic wholes. In E. Machery, M. Werning, and G. Schurz (eds.), The compositionality of Meaning and Content. Vol I Foundational issues. Frankfurt : Ontos Verlag.

Mari, A. 2009a. Disambiguating the Italian Future. In Proceedings of Generative Lexicon, 209-216.

Mari, A. 2009b. Future, judges and normalcy conditions. Selected talk at Chronos 10, Austin, Texas. https://halshs.archives-ouvertes.fr/ijn_00354462/

Mari, A. 2014. Each Other, asymmetry and reasonable futures. Journal of Semantics, 31(2): 209-261.

Mari, A. 2015a. Modalités et Temps. Bern: Peter Lang AG.

Mari, A. 2015b. French future : Exploring the future ratification hypothesis. Journal of French Language Studies, doi :10.1017/S0959269515000289.

Mari, A. 2015c. Overt and covert modality in generic sentences. Cahiers Chronos 27: 265-288.

Mari, A. 2016. Assertability conditions of epistemic (and fictional) attitudes and mood variation. Proceedings of SALT 26: 61-81.

Mari, A. 2017a. Actuality entailments: when the modality is in the presupposition. In Lecture Notes in Computer Science, Dordrecht: Springer Verlag, pp. 191-210.

Mari, A. 2017b. Belief and assertion. Evidence from mood shift. Talk presented at QSA Konstanz, September 2017. 
Mari, A., Beyssade, C. and Del Prete, F. 2012. Introduction. In A. Mari, C. Beyssade and F. Del Prete (eds.). Genericity. Oxfor: Oxford University Press, pp. 1-92.

de Marneffe, M., C. Manning, and C. Potts. 2012. Did it happen? The pragmatic complexity of the veridicality judgement. Computational Linguistics 38: 300-333.

Mayol, L. and Castroviejo, E. 2013. (Non)integrated evaluative adverbs in questions: A crossRomance study. Language 89(2): 195-230.

Montague, R. 1969. On the nature of certain philosophical entities. The Monist 53, 159-194.

Matthewson, L. Rullmann, H., and Davis, H. 2007. Evidentials as Epistemic Modals: Evidence from St'at'imcets. The linguistic Variation Yearbook 7, 201-254.

Moss, S. 2015. On the semantics and pragmatics of epistemic vocabulary. Semantics and Pragmatics 8: 1-81.

Narrog, H. 2012. Modality, Subjectivity, and Semantic Change. Oxford University Press.

Nielsen, Ø. 2004. Domains for adverbs. Lingua, 114(6): 809-847.

Palmer, F.R. 1987. Mood and Modality. Cambridge UP.

Portner, P. 1998. The Progressive in Modal Semantics. Language 74(4): 760-87.

Portner, P. 2009. Modality. Oxford University Press.

Portner, P. and Rubinstein, A. 2016. Extreme and non-extreme deontic modals. In N. Charlow and M. Chrisman (eds.), Deontic Modality. Oxford: OUP.

Potts, C. 2005. The logic of conventional implicature. Oxford: Oxford University Press.

Potts, C. 2007. The expressive dimension. Theoretical Linguistics 33(2):165-197.

Progovac, L. 1994. Positive and Negative polarity: A binding approach. Cambridge: Cambridge University Press.

Rizzi, Luigi. 1997. The fine structure of the left periphery. In L. Haegeman (ed.). Elements of Grammar: A Handbook of Generative Syntax. Dordrecht: Kluwer. 281-337.

Rubinstein, A. 2014. On Necessity and Comparison. Pacif Philosophical Quaterly 95: 512-554.

Smirnova, A. 2013. Evidentiality in Bulgarian. Journal of Semantics: 1-74.

Stephenson, T. 2007. Judge dependence, epistemic modals, and predicates of personal taste. Linguistics and Philosophy, 30(4): 487-525.

Szabolcsi, A. 2004. Positive polarity - Negative polarity. Natural Language and Linguistic Theory 22, 409-452.

Yalcin, S. 2007. Epistemic modals. Mind 116: 983-1026.

Tonhauser, J., Beaver, D., Roberts, C. and Simons, M. 2013. Toward a taxonomy of projective content. Language 89(1): 66-109.

Willer, M. 2013. Dynamics of Epistemic Modality. Philosophical Review 122: 45-92.

Willett, T. 1988. A cross-linguistic survey of the grammaticalization of evidentiality. Studies in Language 12: 51-97.

Wolf, L. 2013. Degrees of Assertion. PhD Dissertation, Ben Gurion University. van der Wouden, T. 1994. Negative Contexts. PhD. University of Groningen.

Zanuttini, R. 1992. Negation and Clausal Structure: A Comparative Study of Romance Languages. $\mathrm{PhD}$ thesis Penn.

Zeijlstra, E. forthcoming. Universal quantifiers PPIs. To appear in Glossa.

Zwarts, F. 1995. Nonveridical contexts. Linguistic Analysis. 